\title{
Nuclear Characterization of a General-Purpose Instrumentation and Materials Testing Location in TREAT
}

John D. Bess, Nicolas E. Woolstenhulme, Colby B. Jensen, James R. Parry, Connie M. Hill

February 2019

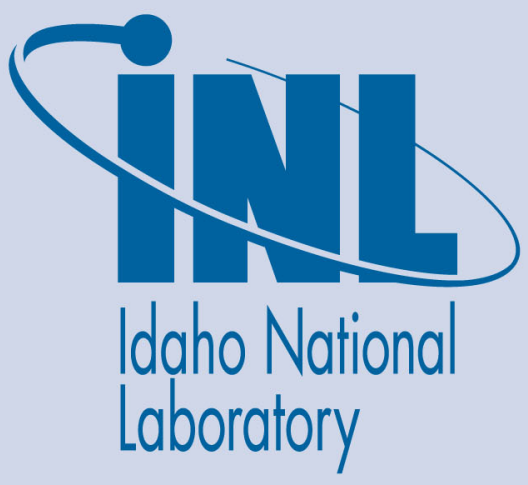

The INL is a U.S. Department of Energy National Laboratory operated by Battelle Energy Alliance 


\section{Nuclear Characterization of a General-Purpose Instrumentation and Materials Testing Location in TREAT}

John D. Bess, Nicolas E. Woolstenhulme, Colby B. Jensen, James R. Parry, Connie M. Hill

February 2019

Idaho National Laboratory Idaho Falls, Idaho 83415

http://www.inl.gov

Prepared for the

U.S. Department of Energy

Under DOE Idaho Operations Office

Contract DE-AC07-05ID14517 


\title{
Nuclear Characterization of a General-Purpose \\ Instrumentation and Materials Testing Location in TREAT
}

\author{
John D. Bess - ORCID: 0000-0002-4936-9103 -John.Bess@inl.gov \\ Nicolas E. Woolstenhulme - ORCID: 0000-0002-7881-3314 - Nicolas.Woolstenhulme@inl.gov \\ Colby B. Jensen - ORCID: 0000-0001-8925-7758 - Colby.Jensen@inl.gov \\ James R. Parry - ORCID: 0000-0003-2837-2626 - James.Parry@inl.gov \\ Connie M. Hill - ORCID: 0000-0003-3504-9421 - Connie.Hill@inl.gov \\ Idaho National Laboratory, 2525 N. Fremont Ave, Idaho Falls, Idaho 83415
}

\author{
Corresponding Author: \\ John D. Bess \\ Idaho National Laboratory, 2525 N. Fremont Ave, \\ P.O. Box 1625, MS 3855, Idaho Falls, Idaho 83415 \\ Phone: (208) 523-1766,Email:John.Bess@INL.gov
}

Total Number of Pages: 71

Total Number of Tables: 10

Total Number of Figures: 22 


\title{
Nuclear Characterization of a General-Purpose
}

\section{Instrumentation and Materials Testing Location in TREAT}

\author{
John D. Bess, Nicolas E. Woolstenhulme, Colby B. Jensen, James R. Parry, Connie M. Hill \\ Idaho National Laboratory, 2525 N. Fremont Ave, Idaho Falls, Idaho 83415
}

\begin{abstract}
The Transient Reactor Test facility (TREAT) was constructed in the late 1950s, provided thousands of transient irradiations before being placed in standby in 1994, and resumed operations in 2017 in order to reclaim its crucial role in nuclear-heated safety research. The latter half of TREAT's historic operation was best known for integral-scale testing of fuel specimens under postulated reactor plant accident conditions, while TREAT's earlier history included extensive simpler phenomena identification tests that elucidated fundamental behaviors and paved the way for these integral-scale tests. Advances in modern computational capabilities and a resurgence of interest in novel reactor technology have created an opportunity for emphasizing modernized science-based and separate effects test capabilities once again at TREAT. An innovative approach to this type of testing has been developed to leverage minor radioactivity built-in during brief TREAT irradiations in low activation hardware to facilitate handling for materials and instrumentation testing. This capability, termed the Minimal Activation Retrievable Capsule Holder (MARCH) irradiation vehicle system, will be used for inaugural fueled experiments in TREAT's modern era as well as novel approaches to study materials undergoing neutron irradiation and instrumentation development and qualifications. This paper describes a comprehensive nuclear characterization, obtained via computational modeling, for the Materials and Instrumentation Modular Irradiation Capability (MIMIC) module in the Broad
\end{abstract}


Use Specimen Transient Experiment Rig (BUSTER) test position of the MARCH system. Though results are directly applicable to MIMIC and BUSTER, they also provide general quantification of the nuclear performance of the reactor and potential test materials, crucial for evaluating potential experiment design and response in TREAT. The neutron and photon flux environments were calculated via MCNP with ENDF/B-VII.1 nuclear data. Wire heating rates and atomic displacement calculations were also performed; sample calculations using historic TREAT operational data were provided to demonstrate example conditions. These calculations were performed to provide steady-state baseline reference values typical in both half- and fullslotted TREAT core configurations, enabling design scoping analysis prior to development of more specific design testing needs and transient testing experimentation. Due to the limited availability of historic data to validate current calculations, validation experiments are planned once the BUSTER test vehicle has been constructed.

Keywords - In-Pile Instrumentation, Irradiation Environment, MCNP, Nuclear Testing, Reactor Characterization, Transient Testing

\section{Highlights-}

- MARCH irradiation vehicle system to be used for inaugural TREAT experiments

- Transient testing needs and TREAT capabilities discussed

- Baseline characterization of BUSTER/MIMIC irradiation test environment performed

- MCNP scoping calculations of neutron flux, photon flux, DPA, and wire heating rates

- Sample calculations based upon historic operational data provided for comparison 


\section{Introduction}

\subsection{Transient Reactor Test (TREAT) Facility}

TREAT is an air-cooled reactor composed of graphite blocks encapsulated in zirconium alloy canisters (Freund et al., 1958). A dilute concentration of uranium oxide is dispersed in the blocks so that transient nuclear heating is distributed rapidly into the graphitic heatsink/moderator to cause a neutron energy spectral shift with strong negative temperature feedback for safe self-limiting power excursions (MacFarlane et al., 1958). Automaticallycontrolled hydraulic transient rod drives enable virtually any power history within the core's energy capacity of $2500 \mathrm{MJ}$, limited only by the speed of the rods. More than just a pulse reactor, TREAT is also a shaped-transient reactor where inherently-safe core physics, nimble transient rod drive systems, and a philosophy of continual facility improvement work together to enable flexible power maneuvers relevant to current-fleet nuclear plants, advanced reactors, and scientifically-valuable power shapes. TREAT experiments are typically lowered into the core through an opening in the upper rotating shield. Radioactive experiments are handled outside of the reactor with shielded casks. Experiment devices typically displace a few driver fuel assemblies, each being approximately $10-\mathrm{cm}$-square, in the central region of the $1.2 \mathrm{~m}$ activelength core. TREAT experiment vehicles are typically self-contained assemblies with engineered capabilities to safely contain any hazards, support specimens/instrumentation, and provide the desired specimen boundary conditions (Woolstenhulme et al., 2014). An isometric overview of TREAT's primary features can be seen in Fig. 1. An overhead schematic of the TREAT facility is provided in Fig. 2. 


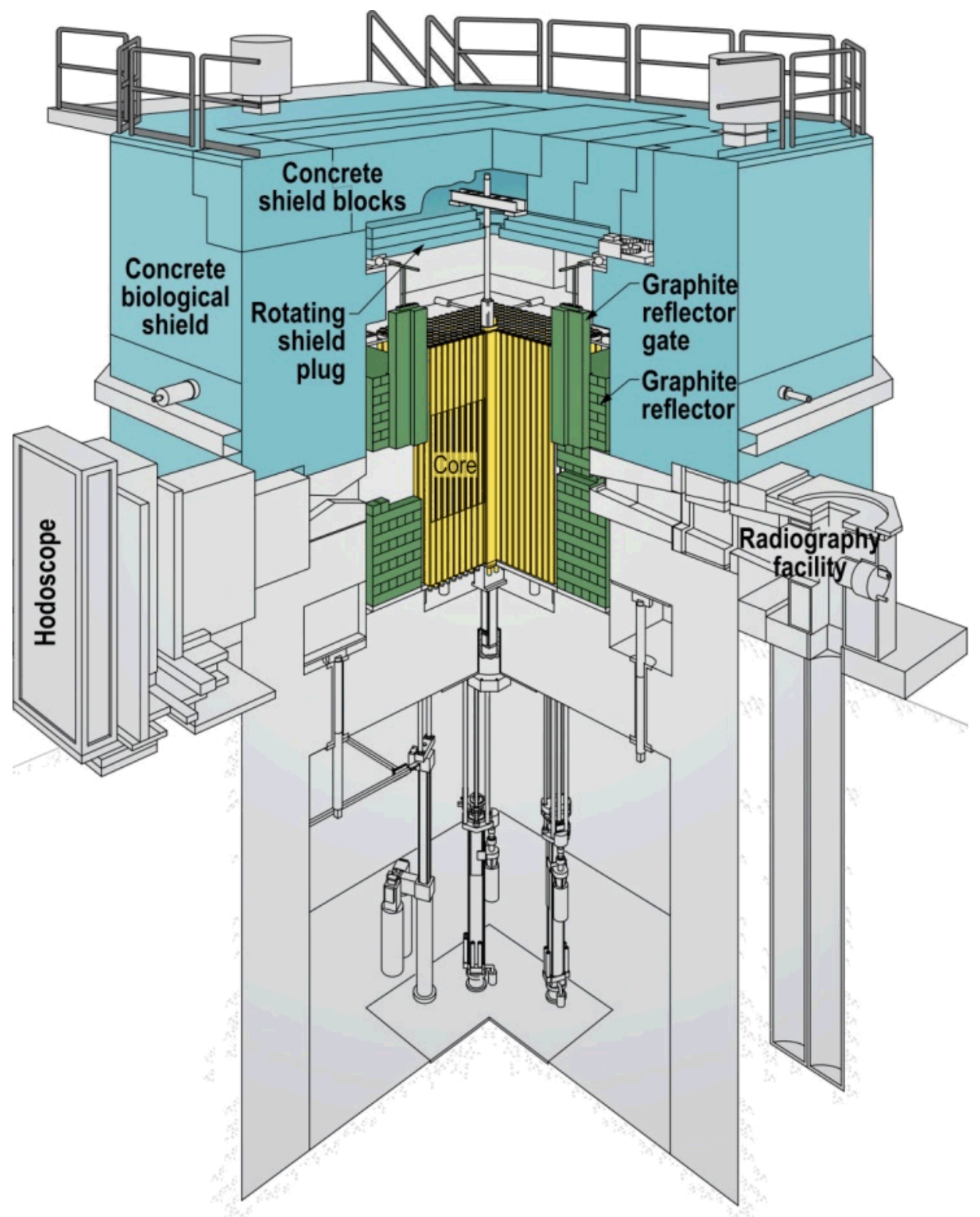

Fig. 1. Isometric Overview of TREAT Features, 3/4 Section View (Bess and DeHart 2015). 


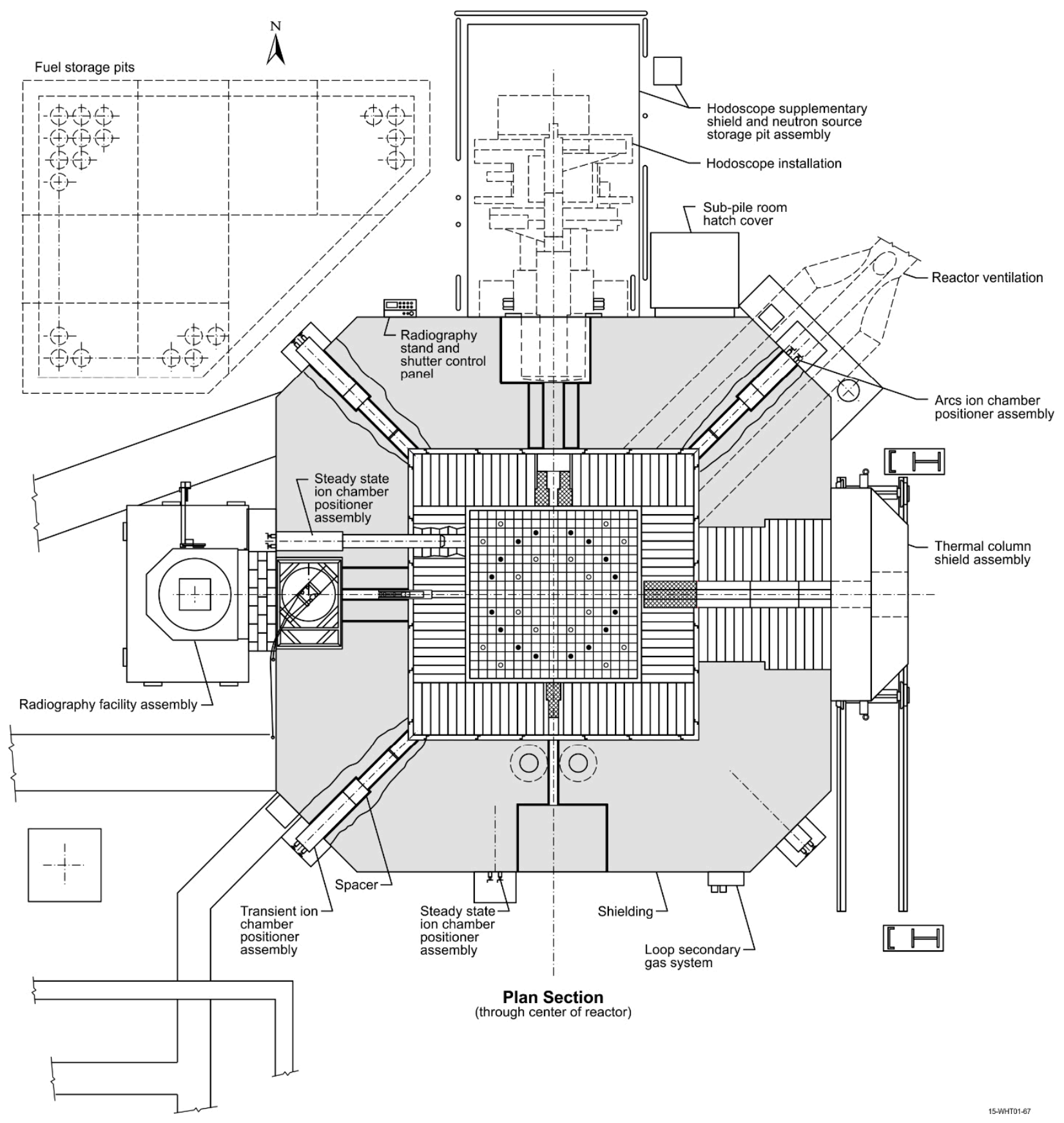

Fig. 2. Overhead Layout of Primary TREAT Facility Features. 
TREAT's cooling system is more than sufficient for steady-state operation at $120 \mathrm{~kW}$ thermal power; operation at this steady-state power is useful for physics measurements, accumulation of isotopes (such as ${ }^{131} \mathrm{I}$ ) to measure their release in follow-on tests, neutron radiography, and other operations necessary for system check-out. Transients can be shaped to vary over several orders of magnitude in power, total energy, and transient duration. An Automatic Reactor Control System (ARCS) interfaces with experiment diagnostics instruments to enable feedback control and synchronization of experiment boundary conditions (nuclear, thermal hydraulic, etc.). Generally transient testing is thought of as the study of nuclear fuels and materials under events changing in instantaneous conditions. In-pile nuclear-heated transient testing provides rapid power excursions, representative distributions of specimen heat generation, and coupled irradiation effects. TREAT's relatively basic design, augmented by decades of incremental facility upgrades, create an extraordinary capability for nuclear-heated transient testing. TREAT's power maneuvering capability, when paired with experiment vehicles that provide specimen boundary conditions, complemented by in-situ instrumentation, and collocated with post-transient examination facilities, produce a full capability package able to address data needs for practically any reactor type or accident category.

Even though the core design is relatively simple, its small size relative to the mean free path of neutrons in graphite fuel can challenge many analysis methods. Historically relatively crude methods were supplemented by extensive experimental calibration measurements to estimate power deposition in an experiment, with significant uncertainty. Modern analysis methods for TREAT were not actively pursued since it was last operated in 1994 until more recently with restart in 2017. During that time, there has been a significant loss in knowledge 
and experience to simulate TREAT experiment performance and usage of formerly applied methodologies are now obsolete. The use of current modeling and simulation capabilities to characterize TREAT provides the step forward in developing testing environments supporting modern experimentation design in preparation of advanced modeling and simulation techniques (Bess and DeHart 2015, DeHart et al., 2016).

\subsection{The MARCH System}

The genesis of the Minimal Activation Retrievable Capsule Holder (MARCH) system concept emerged to support experiments aimed at irradiation of small metal fuel alloys in wellmonitored environments in order to characterize the resulting microstructural changes for development of lower-length scale models. It is important to note that MARCH is not an experiment vessel itself; instead, it is a system of components including an outer containment vessel and different modules that can be utilized within the containment vessel. The module selected will depend upon the nature of the experiment to be performed. Although TREAT is not an efficient reactor for long-term sustained chronic irradiation damage, its ease-of-access for in-situ instrumentation and ability to accept uranium/plutonium-bearing samples from adjacent facilities at Idaho National Laboratory make it well-suited for irradiations intended to reveal fundamental damage mechanisms in acute exposures.

Three core components of the MARCH system have been developed in order to support this irradiation and others like it including: a containment structure termed the Broad Use Specimen Transient Experiment Rig (BUSTER), a high temperature heater module (capable of up to $700{ }^{\circ} \mathrm{C}$ electrical preheat), and a test module tailored to encapsulate small specimens for 
specific testing needs, such as the Characterization-scale Instrument Neutron Dose Irradiation (CINDI) module. A fundamental feature of the MARCH system is its modular layout. In this arrangement the BUSTER comprises the engineering burden of a safety containment so that modules placed within its $6 \mathrm{~cm}$ useable inner diameter can be engineered from more exotic materials and/or to less exacting consensus standard requirements. The end result is a highly adaptable system which supports cost effective, high throughput, and rapid innovation cycles in irradiation experiments.

Other modules have also been designed to serve various separate-effects and limitedcombined effects irradiations. One of these modules, termed the Separate-Effect Test Holder (SETH), enables transient irradiations of various "centimeter-scale" fuel specimens for separateeffects tests such as melt progression studies, phenomena identification, and in-situ properties measurements. The SETH module's larger capsule displaces the BUSTER heater module and is filled with room temperature inert gas in order to facilitate stable boundary conditions for experiments with reduced engineering/fabrication burden for performing separate effects tests. The SETH capsule is able to be arranged with low-activation materials and off-the-shelf consumables, combining to create a well-placed tool for timely and cost-effective science-based irradiations.

The development of a new, revolutionary module concept has been initiated to constitute a safety/engineering envelope enabling irradiation of simple specimens, such as instrumentation, to be performed as affordably as typical out-of-pile testing. While this module, termed the Materials and Instrumentation Modular Irradiation Capability (MIMIC) includes some basic hardware, its true innovation is a safety analysis philosophy based on pre-populated 
nuclear/thermal parameters in a straightforward calculation tool. The MIMIC analysis module permits safe irradiation of pre-analyzed materials based only on their constituent masses; bypassing the cost of geometric-specific modeling/reporting. This module capability is especially relevant for instrumentation testing, as described in the following section. The present work was performed to support a comprehensive nuclear characterization, via modeling, of the BUSTER's experiment cavity in order to support evaluations and strategic planning for instrumentation development irradiations in TREAT. An overview image of the MARCH system can be seen in Fig. 3. A more detailed rendering of the MIMIC module can be seen in Fig. 4 (Woolstenhulme et al., 2018). The BUSTER containment module is used for all experiments within the MARCH test system. Modules such as CINDI, SETH, MIMIC, or future module designs, can be placed within BUSTER to support specific testing requirements. Figure 4 demonstrates the flexibility in MIMIC module design allowing for the testing of specific instrumentation components within a heated transient irradiation environment. 


\section{The MARCH System}
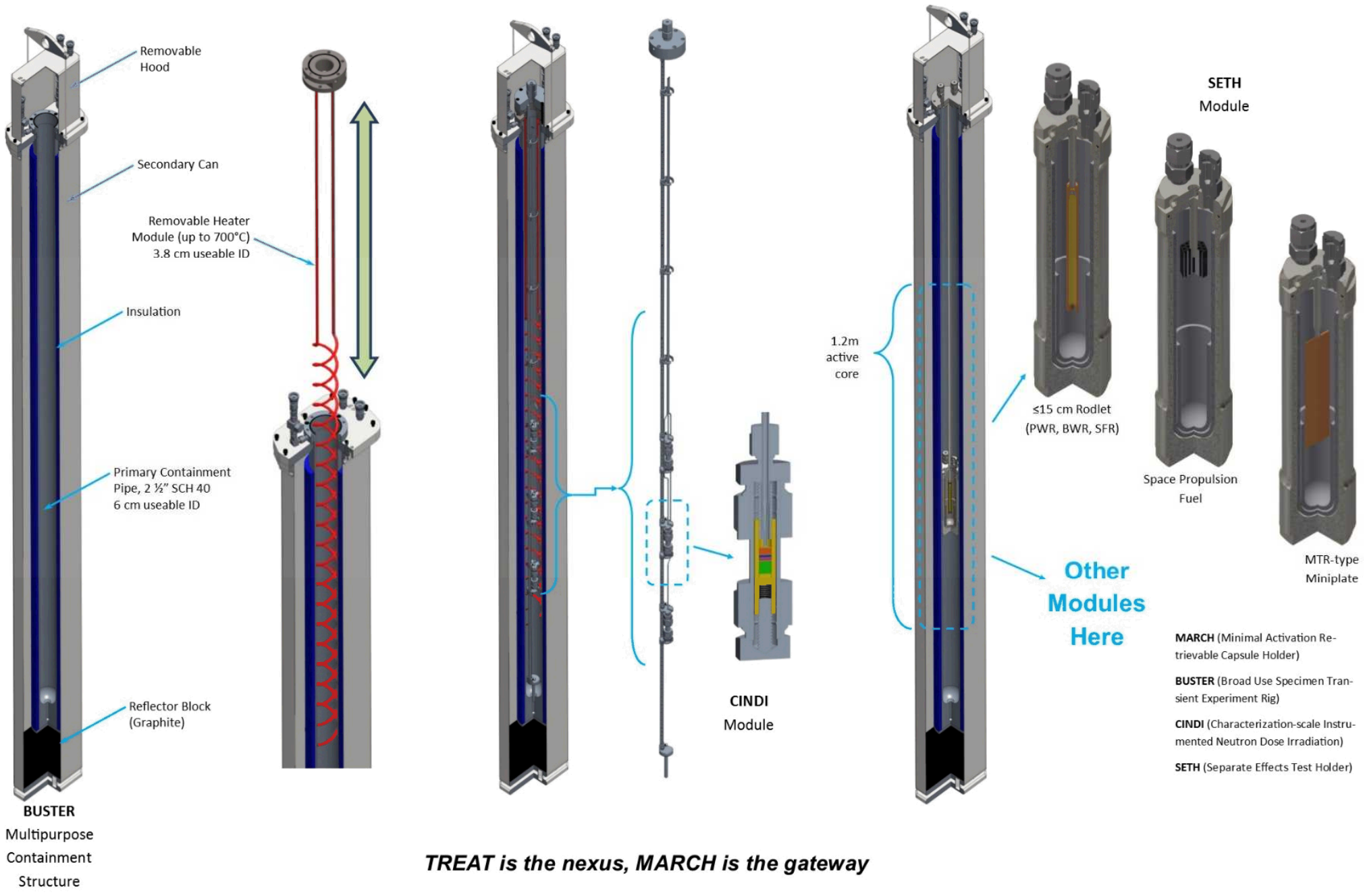

TREAT is the nexus, MARCH is the gateway

Fig. 3. Overview of the MARCH System. 


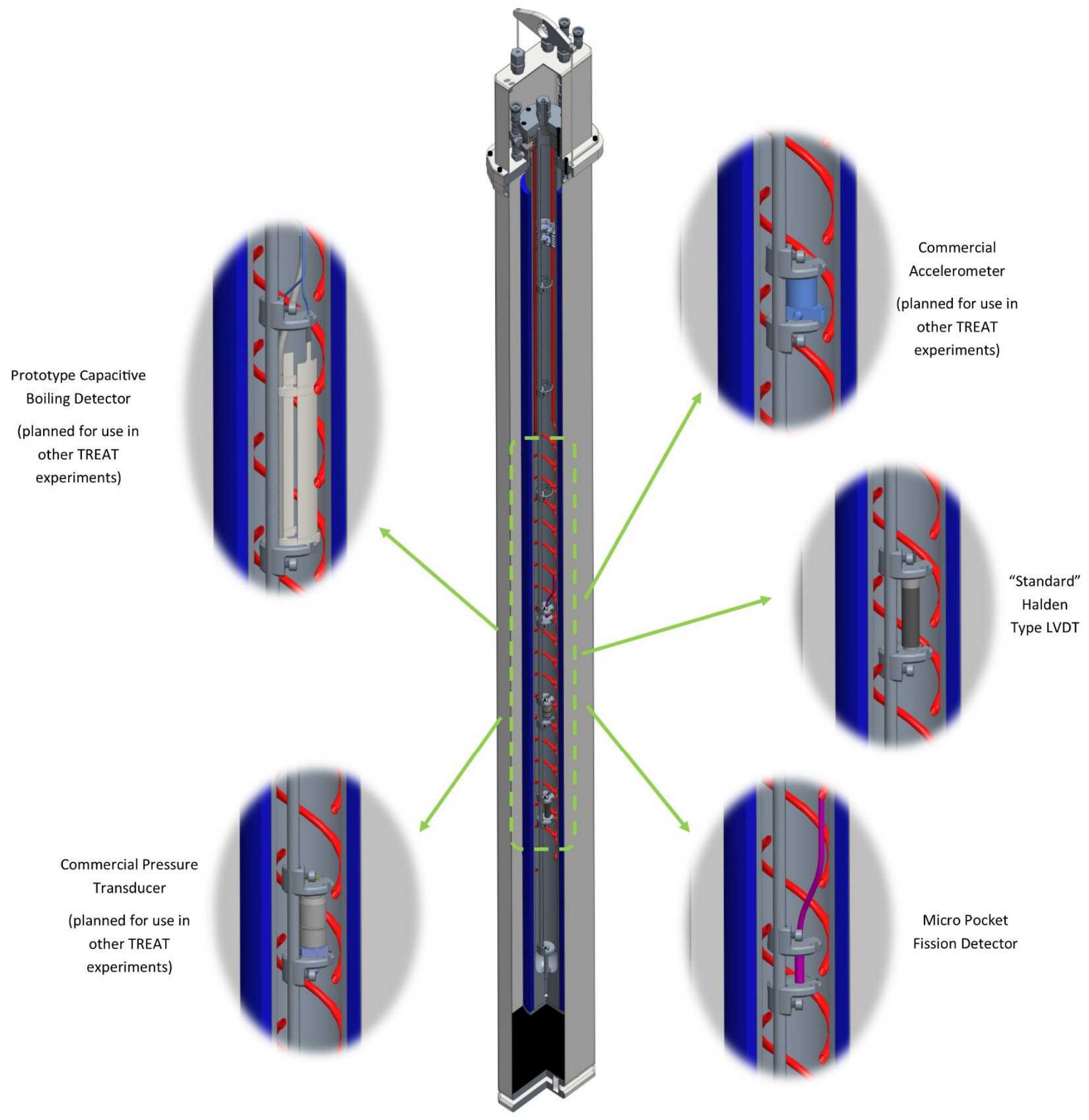

Fig. 4. Example Instruments using MIMIC in Heater Module 


\subsection{Irradiation Testing Needs}

In-pile sensor research and development $(R \& D)$ focuses on development of novel sensors, maturation of current measurement technologies, and adaptation of state-of-the art instruments to measure performance, properties, and boundary conditions of nuclear fuels/materials under irradiation in nuclear reactors. The ultimate goal of in-pile sensor R\&D efforts is qualification of a sensor for its ultimate measurement application. Instrument qualification is defined as using a science-based approach to provide documented evidence that an instrument is capable of operating within established limits and tolerances for its intended purpose when properly installed, maintained, and calibrated. For in-pile sensors, the performance of the sensor under irradiation may be unique for well-established technologies, and thus, is crucial and potentially a pivotal component of sensor development and qualification testing.

Generally speaking, in-pile applications of sensors can be categorized as designed for either steady-state or transient irradiations. Steady-state irradiations typically make use of material test reactors to accumulate damage and measure data throughout experiment durations lasting months to years. Conversely, transient irradiations make use of transient test reactors where irradiations last seconds to minutes. Most test reactors operate steady-state with limited transient capabilities; combining reactors such as the Advanced Test Reactor (ATR) with TREAT can maximize steady-state irradiations while then enabling transient irradiation testing.

Steady-state irradiations are often intended to reveal performance phenomena and limitations of fuels/materials when everything is "proceeding as planned" at nuclear plants. As such, steady-state irradiations are often focused on developing data which supports the economics of nuclear fuel applications. Transient testing, which is generally thought of as the study of nuclear fuel under power- 
cooling mismatches, is typically meant to reveal performance under postulated unplanned conditions. As such, transient testing is often focused toward safety and regulatory data needs; in many cases making it of principle importance for advanced concepts seeking to license novel technologies. Steady-state irradiations are also used to condition specimens for use in transient testing. Both irradiation types provide data that is useful for validating predictive methods or for extending the knowledge and understanding for fuels and materials.

Both types of irradiation testing require in-situ data, and in some cases can employ common technologies. In other cases, these two types of irradiation can differ dramatically in their instrumentation needs. Development of steady-state, in-pile instruments has often fixated on the nontrivial problem of sensor survival under long-term exposure (e.g. material damage from fast neutron fluences). Transient instruments, on the other hand, must be developed to respond rapidly to and endure acute exposure from extreme nuclear and thermal conditions over a short period of time.

The motivation behind the work reported herein is to establish a foundational capability to facilitate instrument testing in TREAT. The link between general purpose TREAT instrument irradiation capability and the development of transient instruments is quite natural. TREAT's characteristics, however, can also fill another capability gap for steady-state instruments early in their maturation cycle before investment in long-term ATR or similar irradiations. Steady-state reactors represent the end use of many in-pile sensor technologies, making the design/installation cost and immense irradiation durations an unavoidable circumstance where long-term neutron damage is a primary data condition. However, TREAT's lack of water and reactor pressure vessel greatly reduces the cost of instrument lead routing and experiment installation, while unparalleled power maneuvering capabilities make TREAT 
apt for numerous sensor irradiation objectives. Examples of such objectives include temporal response and measurement sensitivity to a wide range of neutron and gamma radiation flux magnitudes.

TREAT tests can help reveal phenomena behind reactor-induced sensor damage for material/concept screening both for novel sensors and evaluating available technologies for use in subsequent transient tests (e.g. TREAT capsules and loops). TREAT irradiations can also help determine the response range for nuclear instruments under well-controlled and -specified conditions and quantify "nuclear noise" in other instruments. In some cases, TREAT-based instrument qualification tests can be used to demonstrate that instruments are ready to make their intended measurements in a nuclear environment (Woolstenhulme et al., 2017).

The accessibility and overall flexibility for instrumentation afforded by TREAT as well as its power maneuverability provides a unique capability to affordably build and execute simplified material experiments under irradiation. This category of testing includes development of instrumentation approaches requiring a measurement material subject, such as extrinsic optical diagnostics. These experiments may include fissionable and non-fissionable material subjects though depending on total mass, fissionable material likely brings added costs. Many advanced laboratory-based materials characterization measurement techniques can be adapted for application inside TREAT to access on-line irradiation effects, which is of great interest for material properties, chemistry, and microstructure experiments and diagnostics development. As will be shown, neutron dose in TREAT is generally small, though for short duration experiments ranging from milliseconds to several minutes a wide range of neutron flux levels may be achieved. 


\section{Analysis Methods}

\subsection{Computational Modeling of TREAT}

Computational modeling and simulation of TREAT was performed running Monte Carlo NParticle (MCNP) ${ }^{\circledR}$ (X-5 Monte Carlo Team 2014) version 6.1.1 (Goorley 2014) on the Falcon cluster of INL’s High Performance Computing (HPC) systems. Modern model and simulation efforts regarding the TREAT facility have been previously performed and compared against historic operational data to demonstrate satisfactory neutronics performance (Newell 2015, Chipman 2017). Evaluated nuclear data libraries ENDF/B-VII.1 (Chadwick et al., 2011) and ENDL92 (Frankle 1996) were utilized to provide cross section data. ENDF/B-VII.1 was used for most isotopes; ENDL92 was used for the elements of neon and platinum. Evaluation of promethium, ytterbium, osmium, neptunium, and elements with atomic numbers between 84 to 89 , as well as 95 and greater were not included in this study; however, some could be included, as feasibly necessary, in future studies. All MCNP calculations were performed with 1,000 cycles (after discarding an initial 100 cycles) with 1,000,000 particles per cycle for a total of one billion particle histories. Isotopic abundances and nominal mass densities for each element were obtained from the $17^{\text {th }}$ edition of the Chart of the Nuclides (Baum et al., 2010) and used to compute atom densities used in the MCNP calculations. A summary of materials and their respective densities, utilized in this study, is provided in Table 1. Gas densities were computed for a standard temperature and pressure (STP) of $273.15 \mathrm{~K}$ and $1 \mathrm{~atm}$, respectively. While not all materials will be present during a given MIMIC transient test, they represent possible materials contained within fuels, materials, instruments, or support structure that might be irradiated during future experiment activities. The summary table of materials is provided for initial design planning purposes coupled with the provided results. 
Table 1. Materials Investigated in the Nuclear Characterization Analyses

\begin{tabular}{|c|c|c|c|c|c|}
\hline Material & $\begin{array}{c}\text { Atom Density } \\
\text { (atm/b-cm) }\end{array}$ & $\begin{array}{c}\text { Mass Density } \\
\left(\mathrm{g} / \mathrm{cm}^{3}\right)\end{array}$ & Material & $\begin{array}{c}\text { Atom Density } \\
\text { (atm/b-cm) }\end{array}$ & $\begin{array}{c}\text { Mass Density } \\
\left(\mathrm{g} / \mathrm{cm}^{3}\right)\end{array}$ \\
\hline $\mathrm{H}$ & $2.6869 \mathrm{E}-05$ & $4.50 \mathrm{E}-05$ & Mo & $6.4150 \mathrm{E}-02$ & 10.22 \\
\hline${ }^{2} \mathrm{H}$ & $2.6869 \mathrm{E}-05$ & $8.99 \mathrm{E}-05$ & $\mathrm{Tc}$ & $7.0020 \mathrm{E}-02$ & 11.5 \\
\hline${ }^{3} \mathrm{H}$ & $2.6869 \mathrm{E}-05$ & $1.35 \mathrm{E}-04$ & $\mathrm{Ru}$ & 7.3943E-02 & 12.41 \\
\hline $\mathrm{He}$ & $2.6869 \mathrm{E}-05$ & $1.79 \mathrm{E}-04$ & $\mathrm{Rh}$ & 7.2624E-02 & 12.41 \\
\hline${ }^{3} \mathrm{He}$ & $2.6869 \mathrm{E}-05$ & $1.35 \mathrm{E}-04$ & $\mathrm{Pd}$ & 6.8019E-02 & 12.02 \\
\hline $\mathrm{Li}$ & 4.6331E-02 & 0.534 & $\mathrm{Ag}$ & $5.8620 \mathrm{E}-02$ & 10.5 \\
\hline${ }^{7} \mathrm{Li}$ & $4.5835 \mathrm{E}-02$ & 0.534 & $\mathrm{Cd}$ & 4.6340E-02 & 8.65 \\
\hline $\mathrm{Be}$ & $1.2349 \mathrm{E}-01$ & 1.848 & In & $3.8340 \mathrm{E}-02$ & 7.31 \\
\hline $\mathrm{B}$ & $1.3090 \mathrm{E}-01$ & 2.35 & $\mathrm{Sn}$ & $3.6967 \mathrm{E}-02$ & 7.287 \\
\hline${ }^{10} \mathrm{~B}$ & $1.4134 \mathrm{E}-01$ & 2.35 & $\mathrm{Sb}$ & $3.3093 \mathrm{E}-02$ & 6.691 \\
\hline $\mathrm{C}$ & $1.0028 \mathrm{E}-01$ & 2 & $\mathrm{Te}$ & $2.9450 \mathrm{E}-02$ & 6.24 \\
\hline $\mathrm{N}$ & $2.6869 \mathrm{E}-05$ & $6.25 \mathrm{E}-04$ & I & $2.3395 \mathrm{E}-02$ & 4.93 \\
\hline $\mathrm{O}$ & $2.6869 \mathrm{E}-05$ & $7.14 \mathrm{E}-04$ & $\mathrm{Xe}$ & $2.6869 \mathrm{E}-05$ & $5.86 \mathrm{E}-03$ \\
\hline $\mathrm{F}$ & $2.6869 \mathrm{E}-05$ & $8.48 \mathrm{E}-04$ & Cs & $8.4868 \mathrm{E}-03$ & 1.873 \\
\hline $\mathrm{Ne}$ & $2.6869 \mathrm{E}-05$ & $9.00 \mathrm{E}-04$ & $\mathrm{Ba}$ & $1.5348 \mathrm{E}-02$ & 3.5 \\
\hline $\mathrm{Na}$ & $2.5435 \mathrm{E}-02$ & 0.971 & $\mathrm{La}$ & $2.6641 \mathrm{E}-02$ & 6.145 \\
\hline $\mathrm{Mg}$ & 4.3063E-02 & 1.738 & $\mathrm{Ce}$ & 2.9097E-02 & 6.77 \\
\hline $\mathrm{Al}$ & $6.0238 \mathrm{E}-02$ & 2.6989 & $\operatorname{Pr}$ & $2.8946 \mathrm{E}-02$ & 6.773 \\
\hline $\mathrm{Si}$ & 4.9960E-02 & 2.33 & $\mathrm{Nd}$ & $2.9258 \mathrm{E}-02$ & 7.008 \\
\hline $\mathrm{P}$ & $3.5386 \mathrm{E}-02$ & 1.82 & $\mathrm{Sm}$ & $3.0119 \mathrm{E}-02$ & 7.52 \\
\hline $\mathrm{S}$ & $3.8876 \mathrm{E}-02$ & 2.07 & $\mathrm{Eu}$ & $2.0781 \mathrm{E}-02$ & 5.244 \\
\hline $\mathrm{Cl}$ & $2.6869 \mathrm{E}-05$ & $1.58 \mathrm{E}-03$ & $\mathrm{Gd}$ & $3.0258 \mathrm{E}-02$ & 7.901 \\
\hline $\mathrm{Ar}$ & 2.6869E-05 & $1.78 \mathrm{E}-03$ & $\mathrm{~Tb}$ & $3.1186 \mathrm{E}-02$ & 8.23 \\
\hline $\mathrm{K}$ & $1.3277 \mathrm{E}-02$ & 0.862 & Dy & $3.1689 \mathrm{E}-02$ & 8.551 \\
\hline $\mathrm{Ca}$ & $2.3290 \mathrm{E}-02$ & 1.55 & Ho & $3.2113 \mathrm{E}-02$ & 8.795 \\
\hline $\mathrm{Sc}$ & 4.0039E-02 & 2.989 & $\mathrm{Er}$ & $3.2642 \mathrm{E}-02$ & 9.066 \\
\hline $\mathrm{Ti}$ & $5.7117 \mathrm{E}-02$ & 4.54 & $\mathrm{Tm}$ & $3.3227 \mathrm{E}-02$ & 9.321 \\
\hline V & $7.2230 \mathrm{E}-02$ & 6.11 & $\mathrm{Lu}$ & $3.3871 \mathrm{E}-02$ & 9.841 \\
\hline $\mathrm{Cr}$ & 8.3273E-02 & 7.19 & Hf & 4.4907E-02 & 13.31 \\
\hline $\mathrm{Mn}$ & $8.0020 \mathrm{E}-02$ & 7.3 & $\mathrm{Ta}$ & $5.5426 \mathrm{E}-02$ & 16.654 \\
\hline $\mathrm{Fe}$ & $8.4910 \mathrm{E}-02$ & 7.874 & $\mathrm{~W}$ & $6.3222 \mathrm{E}-02$ & 19.3 \\
\hline Co & $9.0945 \mathrm{E}-02$ & 8.9 & $\mathrm{Re}$ & $6.7981 \mathrm{E}-02$ & 21.02 \\
\hline $\mathrm{Ni}$ & $9.1337 \mathrm{E}-02$ & 8.902 & $\mathrm{Ir}$ & 7.0241E-02 & 22.42 \\
\hline $\mathrm{Cu}$ & $8.4912 \mathrm{E}-02$ & 8.96 & $\mathrm{Pt}$ & $6.6215 \mathrm{E}-02$ & 21.45 \\
\hline $\mathrm{Zn}$ & $6.5672 \mathrm{E}-02$ & 7.133 & $\mathrm{Au}$ & $5.9008 \mathrm{E}-02$ & 19.3 \\
\hline $\mathrm{Ga}$ & $5.0994 \mathrm{E}-02$ & 5.904 & $\mathrm{Hg}$ & $4.0668 \mathrm{E}-02$ & 13.546 \\
\hline $\mathrm{Ge}$ & 4.4129E-02 & 5.323 & $\mathrm{Tl}$ & $3.4916 \mathrm{E}-02$ & 11.85 \\
\hline As & $4.5816 \mathrm{E}-02$ & 5.7 & $\mathrm{~Pb}$ & $3.2988 \mathrm{E}-02$ & 11.35 \\
\hline $\mathrm{Se}$ & $3.5846 \mathrm{E}-02$ & 4.7 & $\mathrm{Bi}$ & $2.8088 \mathrm{E}-02$ & 9.747 \\
\hline $\mathrm{Br}$ & $2.3514 \mathrm{E}-02$ & 3.12 & $\mathrm{Th}$ & $3.0417 \mathrm{E}-02$ & 11.72 \\
\hline $\mathrm{Kr}$ & $2.6869 \mathrm{E}-05$ & $3.74 \mathrm{E}-03$ & $\mathrm{~Pa}$ & $4.0063 \mathrm{E}-02$ & 15.37 \\
\hline $\mathrm{Rb}$ & $1.0795 \mathrm{E}-02$ & 1.532 & $\mathrm{U}$ & 4.7943E-02 & 18.95 \\
\hline $\mathrm{Sr}$ & $1.7457 \mathrm{E}-02$ & 2.54 & ${ }^{235} \mathrm{U}$ & 4.8552E-02 & 18.95 \\
\hline $\mathrm{Y}$ & $3.0271 \mathrm{E}-02$ & 4.469 & ${ }^{238} \mathrm{U}$ & 4.7939E-02 & 18.95 \\
\hline $\mathrm{Zr}$ & 4.2949E-02 & 6.506 & ${ }^{239} \mathrm{Pu}$ & 4.9980E-02 & 19.84 \\
\hline
\end{tabular}

${ }^{*}$ Gas densities calculated from an STP of $273.15 \mathrm{~K}$ and $1 \mathrm{~atm}$. 
The MCNP TREAT core models from design and evaluation of the Multi-SERTTA (Static Environments Rodlet Transient Test Apparatuses) were employed to simulate these experiments (Bess et al., 2016). The Multi-SERTTA test rig was replaced with BUSTER in the M8CAL full-sized core (Robinson and Bauer 1994), which is the current configuration of the core. Scoping studies have shown that the absolute reactivity worth of the MARCH system is significantly less than the M8CAL test vehicle and the Multi-SERTTA test vehicle; therefore, testing will likely occur in a full-slotted core to minimize excess reactivity; the core is currently in a half-slotted configuration. Both half-slotted and full-slotted core models are used in this evaluation.

The primary difference between the half- and full-slotted core configurations is whether a voided region, or slot, running outward from the experiment test vehicle placed in the center of the TREAT core consists of approximately nine or eighteen slotted assemblies, respectively. Slotted assemblies are designed with the fuel section of the assembly replaced by an empty zircaloy frame to create an air channel through the assembly, as shown in Fig. 5. A half-slotted core has nine slotted assemblies placed between the experiment at the center and the edge of the core (typically the north) creating an air channel from core center to one side of the reactor. A full-slotted core adds an additional nine slotted assemblies on the opposite side of the experiment (typically to the south) creating an air channel from one side of the core completely to the other side, only interrupted by the experiment located in the center of the slot. Slotted core configurations typically serve to provide a direct path from the experiment to the fast neutron hodoscope placed to the north side of TREAT as shown in Fig. 1 (De Volpi, et al., 1982 and Chichester, et al., 2015). The half-slotted arrangement requires less fuel removal from the core and results in greater available core excess reactivity than the full slotted arrangement, thus allowing for experiments and vehicles with greater negative worths to be tested, or higher power transient tests to be 
performed. Full-slotted core loadings allow for cleaner hodoscope measurements with reduced background neutron detections from the reactor, as fueled TREAT assemblies are not placed in the direct path of the hodoscope. To facilitate neutron noise reduction in the half-slotted core arrangement, unfueled graphite assemblies can be placed directly to the south of the experiment test vehicle. 


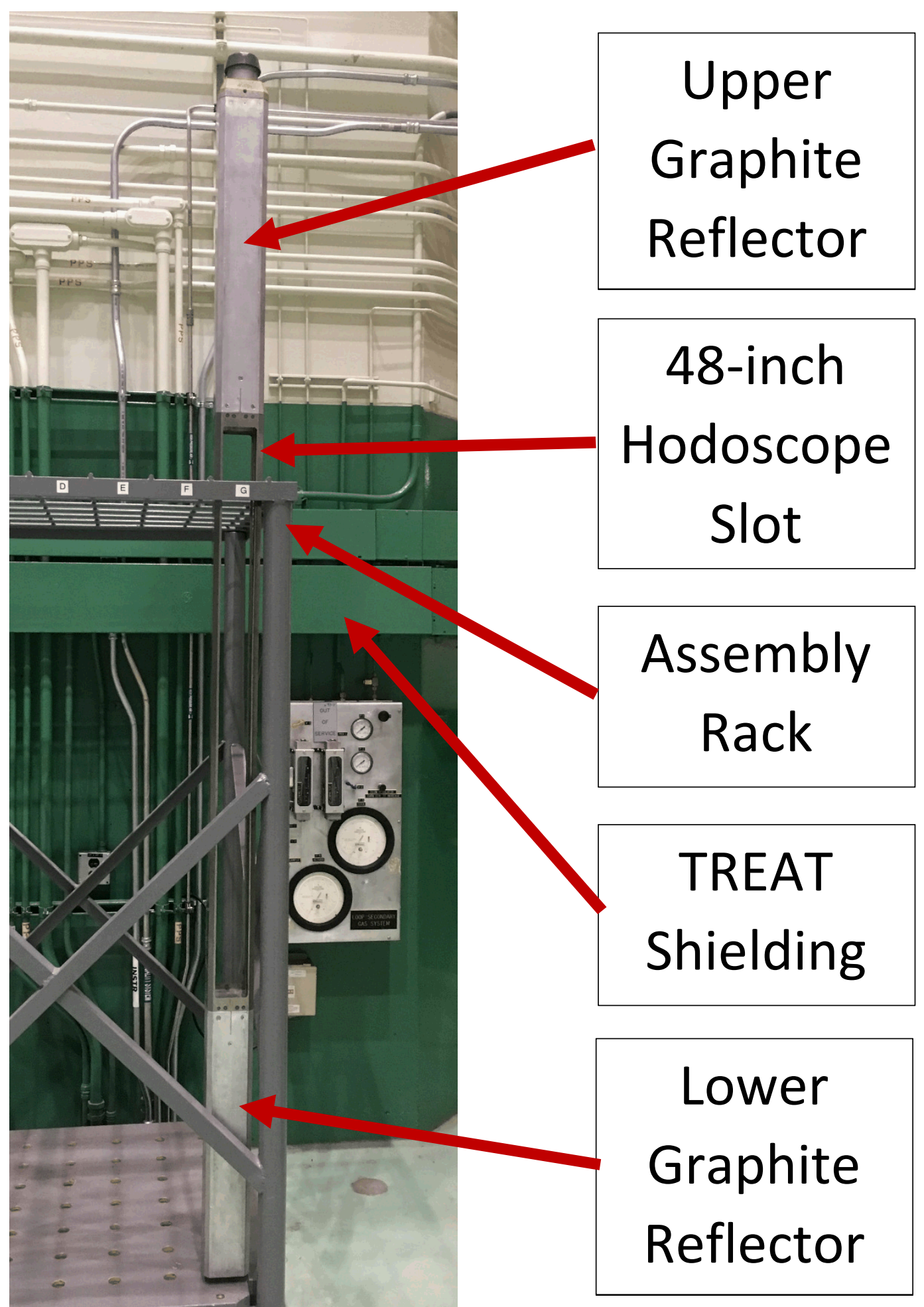

Fig. 5. TREAT 48 in. (121.92 cm) Access Hole (Slotted) Assembly. 
A comparison of typical assemblies used in TREAT are shown in Fig. 6. On the left side of the figure are standard assemblies that contain graphite fuel in the center section; dummy assemblies (not shown) are identical in design to standard fuel assemblies but contain graphite only in the center section. These assemblies may be used adjacent to the core; the Zircaloy cladding is used for thermal protection of the element. Both the control rod and access hole assemblies also typically contained fuel, as shown, but also have non-fueled dummy variants; these assemblies are used to provide a direct airfilled path from the experiment to the ex-core hodoscope. The access hole assembly shown in the center of the figure is $60.96 \mathrm{~cm}$ ( $24 \mathrm{in}$ ) centered along the core mid-plane, with fuel above and below the slotted region. A $121.92 \mathrm{~cm}$ (48 in) variant (shown in Fig. 5) does not contain fuel or graphite within the central section. The top and bottom reflector regions of the assemblies are graphite housed in aluminum. The lead-filled shielding assemblies are not used during normal TREAT operations; they provide shielding, when necessary, during in-core changes between tests. 


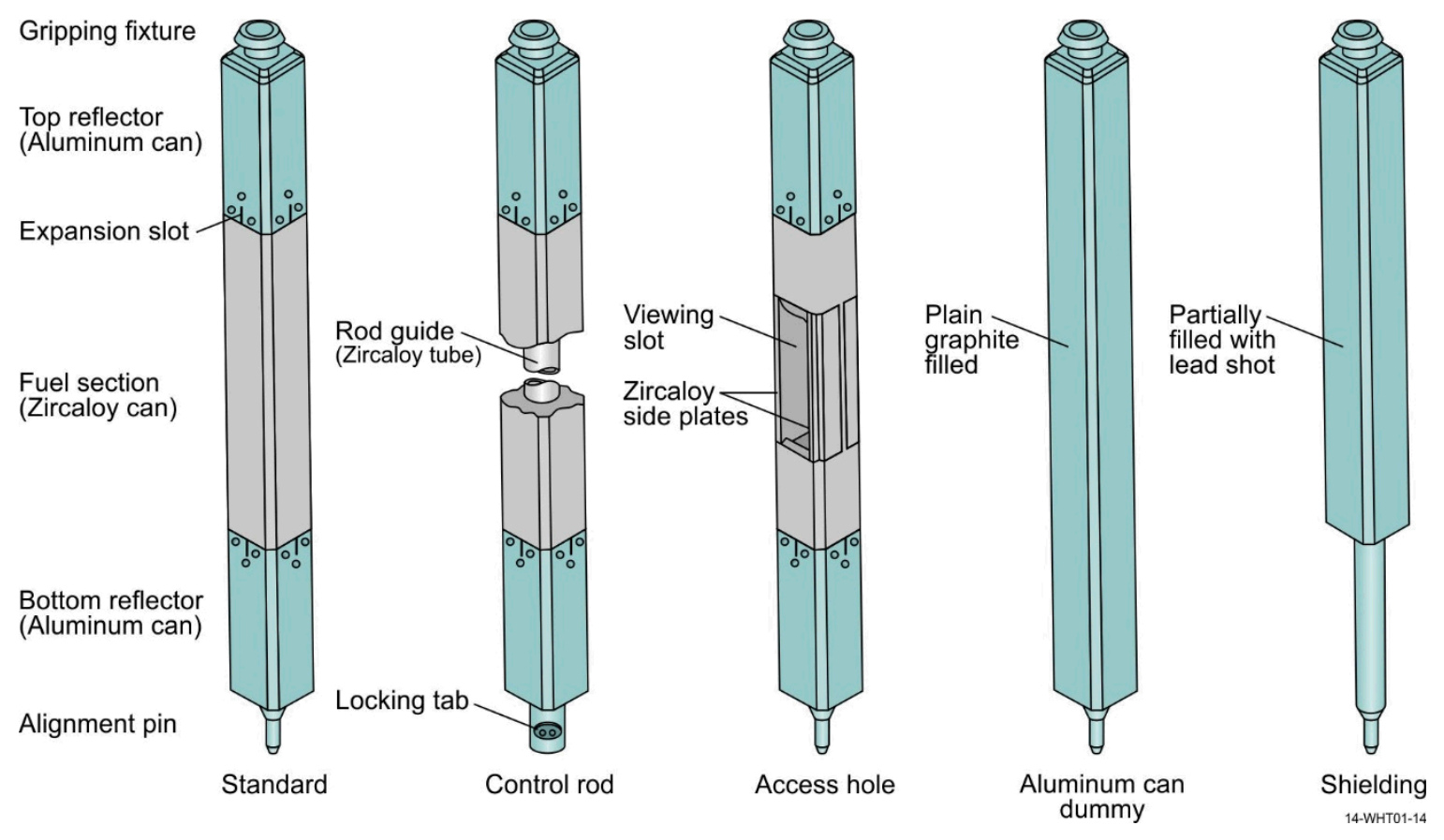

Fig. 5. Typical TREAT Facility Assemblies.

Model plots, including BUSTER inserted into TREAT, are shown in Fig. 7 through Fig. 12. Fig. 7 illustrates the TREAT core loading within the $19 \times 19$ element core and surrounding permanent graphite reflector with hodoscope slot. The orange squares indicate fueled assemblies and the yellow squares indicate dummy assemblies, similar in structure to the fueled assemblies with the absence of $\mathrm{UO}_{2}$ dispersed in the graphite blocks (Bess and DeHart 2015). The dark blue rim surrounding the grid represents an air gap between the permanent reflector and core elements. Slotted assemblies are inserted through the center of the core from north to south to facilitate specimen fast neutron streaming to the hodoscope. The assembly open slot segments (dark blue) are captured in the core mid-plane view. Control rods in Fig. 7 are indicated with circles. The transient rods (yellow) and control/shutdown rods (red) form a ring pattern in the core layout. The compensation rods are also depicted with a yellow circle; however, they are inside the ring and closer to the experiment slot. The compensation rods 
typically are withdrawn during experimentation and inserted into the core to keep the reactor subcritical during experiment loading and unloading. For natural burst operation the reactor is brought critical with all compensation and transient rods fully withdrawn and criticality maintained with the control/shutdown rods partially inserted. Prior to a transient, the transient rods are inserted to a "cocked" position of prescribed worth and the control/shutdown rods partially removed to compensate, maintaining core criticality. The transient rods are then ejected to perform the transient test. All control rods are fully inserted at the end of a transient test.

The experiment, in this case BUSTER, takes up two element slots; however, three slots are used. BUSTER is sandwiched between two half assemblies. The northernmost half assembly has an open slot for hodoscope viewing. The southernmost half assembly is loaded with graphite from the bottom to top of the core. Figures 8 and 9 further illustrate the half assemblies from different views. The vertical cross section view in Fig. 8 shows how BUSTER, from the bottom reflector to the top reflector, is positioned within TREAT. The graphite half assembly (yellow) is filled with graphite from top to bottom; whereas the slotted half assembly has graphite only in the reflector regions. This experimental arrangement is carried over from previous testing in TREAT (Robinson and Bauer 1994). 


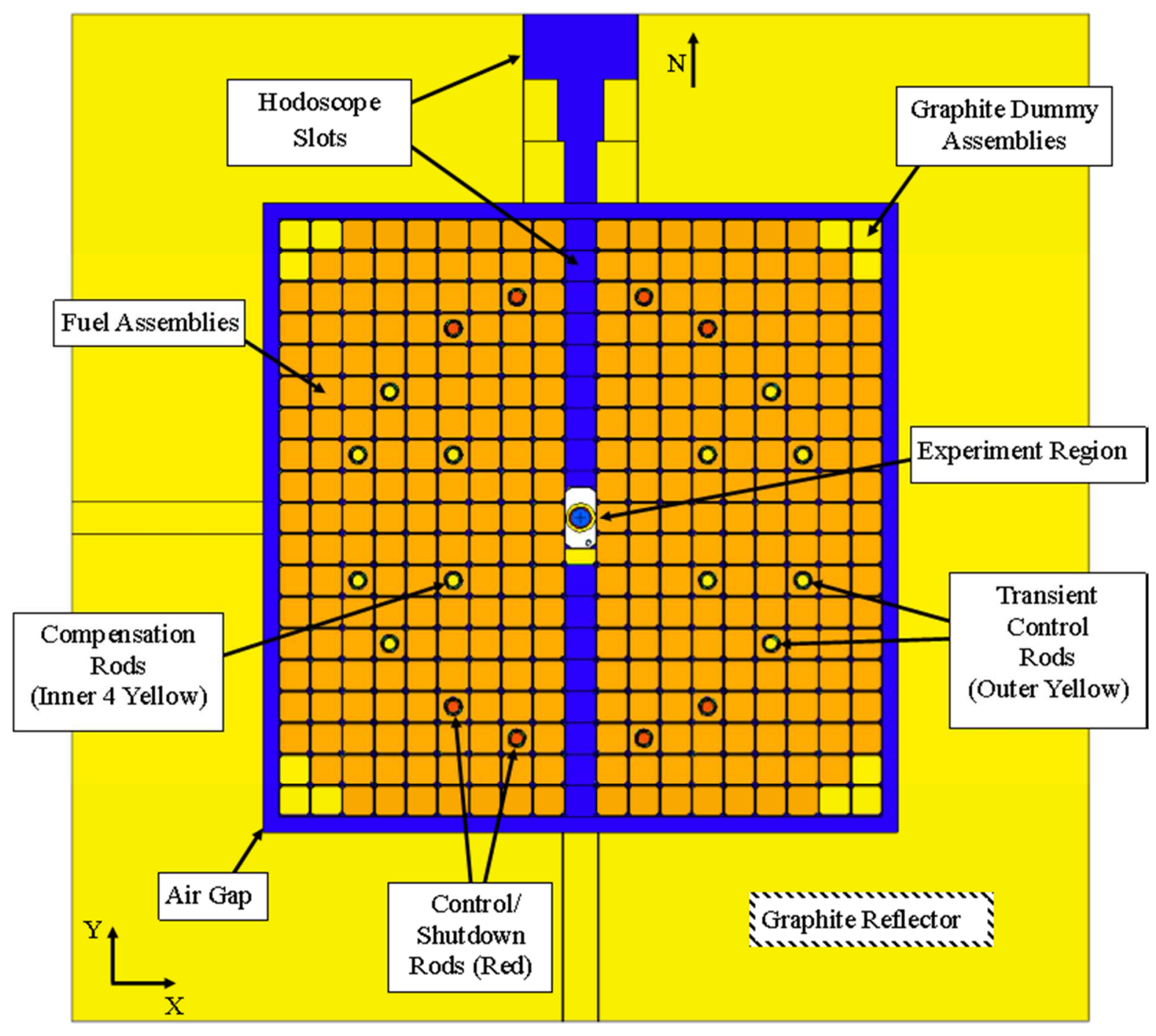

Fig. 7. Horizontal Mid-Plane Plot of TREAT Full-Slotted Core with BUSTER in the Experiment Slot. 


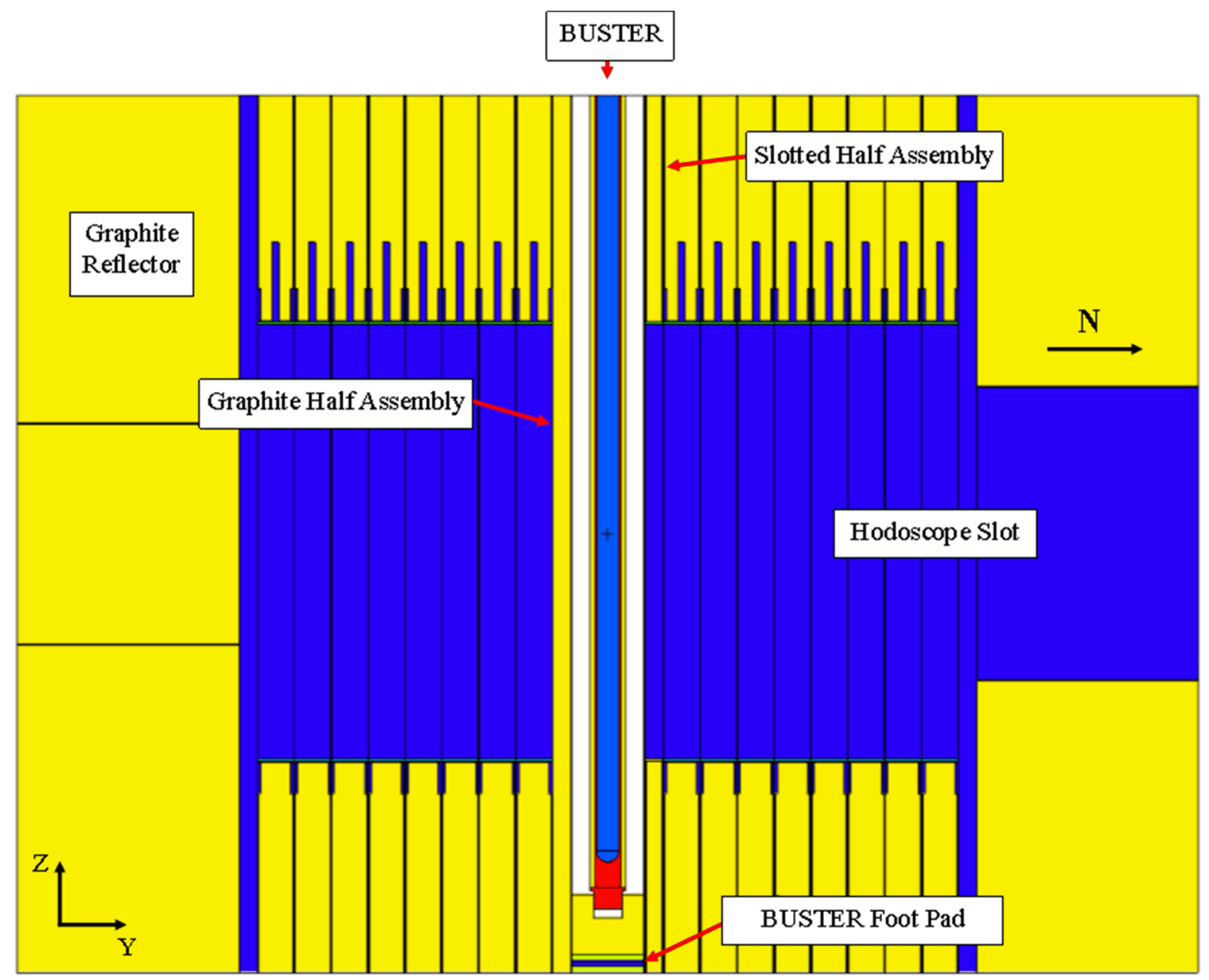

Fig. 8. Vertical Plot (YZ-Plane) of BUSTER Loaded into the TREAT Experiment Slot for the FullSlotted Core Conguration.

The magnified view of the experiment region in Fig. 9 shows in greater detail the contents and basic footprint of the BUSTER in TREAT. The thin-walled outer canister (stainless steel 304) has chamfered corners like the surrounding assemblies to facilitate air coolant flow. These air flow channels are depicted in dark blue. The half assemblies are similar in design to the regular assemblies having the appearance of a full assembly cut directly in half and separate the distance of the experiment insert side length. The primary containment structure (red ring, Fig. 9) is a simple cylindrical stainless steel 316 
pipe positioned in the centermost region of the system. The surrounding MICROSIL ${ }^{\circledR}$ insulation is meant to impede heat exchange between the experiment and the core. The aluminum cover-gas insert tube (blue ring) shown in the lower right corner of the system in Fig. 9 extends from a small cavity in the graphite block to the top of the system. The white volume is filled with $\mathrm{N}_{2}$ cover gas, which was historically used in TREAT experiments to sweep for potential leaks and provide an inert atmosphere to reduce oxidation during the course of a heated experiment. Note that any component above the core upper reflector region is not included in the model, including the BUSTER pipe supporting flange. Exposure to neutron flux in this region is considered negligible. 


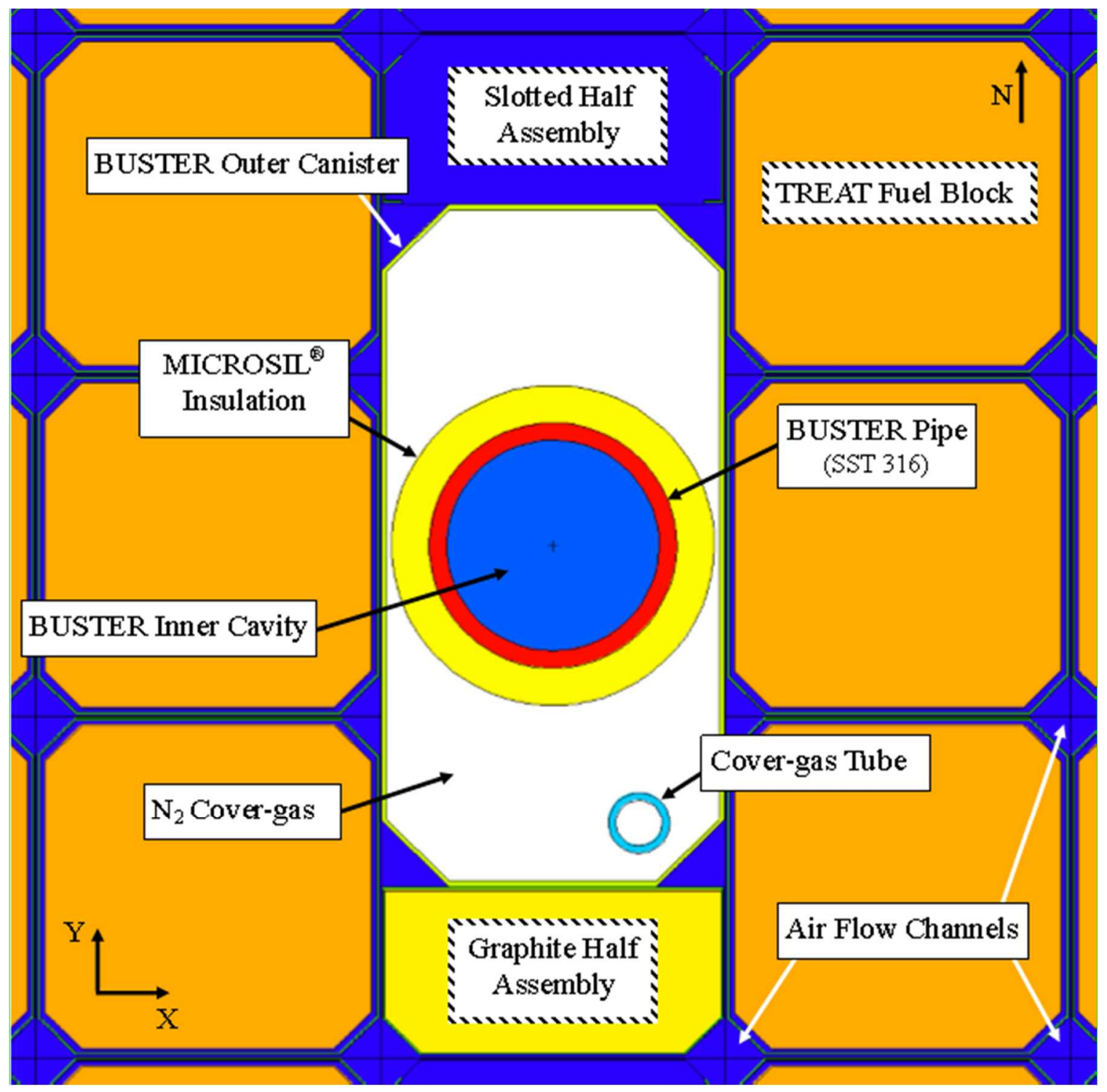

Fig. 9. Magnified Horizontal View of BUSTER.

The cross-sectional view of the BUSTER as shown in Fig. 9 remains the same axially through the active core region and upper reflector region; however, components in the lower reflector region differ and are highlighted in Fig. 10. An endcap (stainless steel 316) is bolted onto the end of the primary containment pipe. This feature is designed to keep the pipe in alignment should the canister be 
placed on its side when handled outside of the core. The bottom of the pipe is solid under the inner cavity (blue) cupped bottom as shown in Fig. 10. The sides of the graphite block form a similar shape to the outer canister leaving a small gap between the canister and block. The outer canister walls are attached to the upper plate of the BUSTER foot pad. The two foot-pad plates shown in Fig. 10 are attached by a set of heavy duty springs in the design.

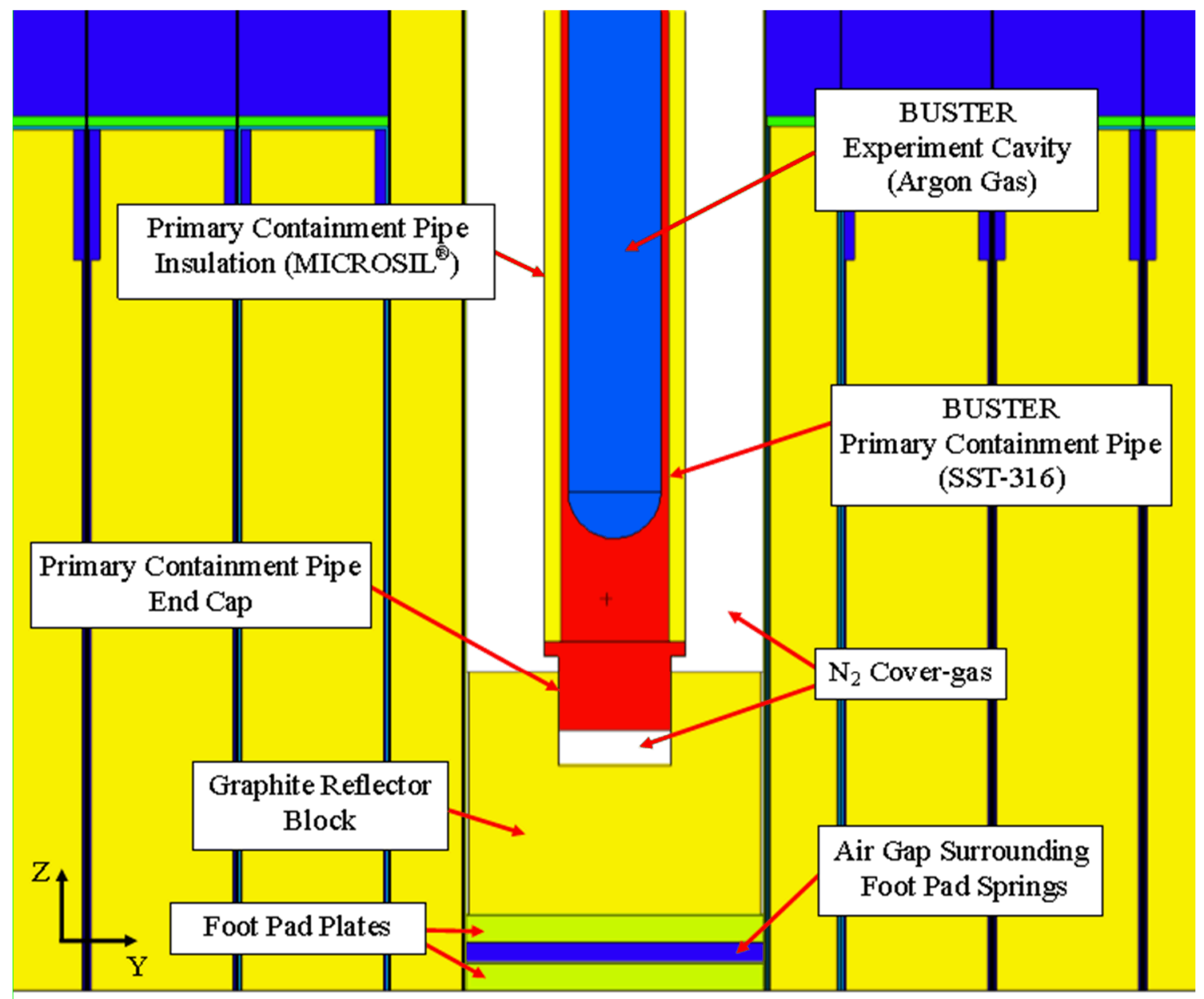

Fig. 10. Magnified Vertical View of BUSTER Components in Lower Core Region. 
Figures 11 and 12 represent the half-slotted core configuration arrangement similar to the fullslotted core layout shown in Figs. 7 and 8, respectively. There are no changes otherwise to the loading of BUSTER in the experimental position of the TREAT core. However, due to an increase in core excess reactivity, the control/shutdown rods would be inserted further into the core to maintain criticality prior to a transient test of similar reactivity insertion to its full-core loading counterpart test.

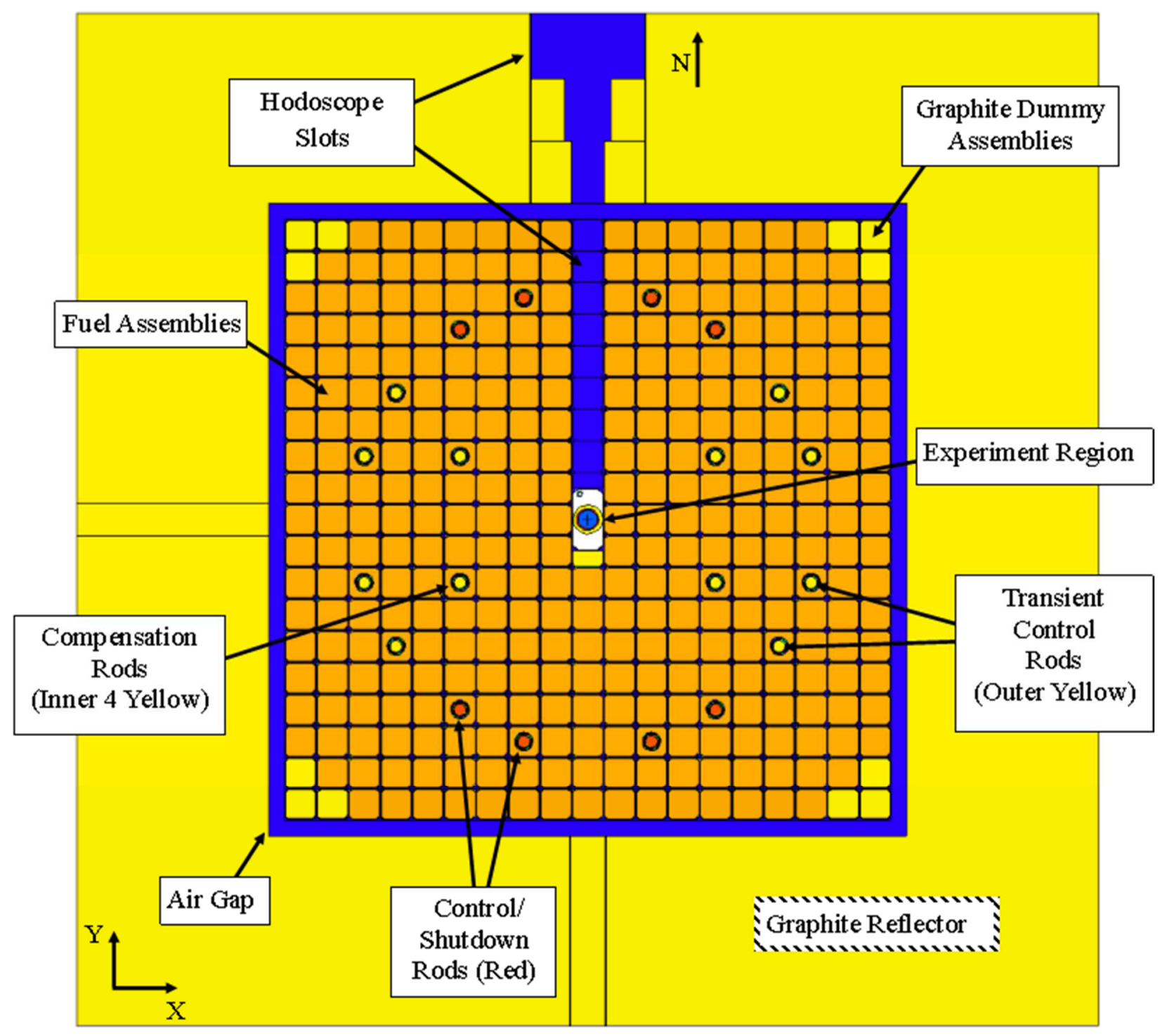

Fig. 11. Horizontal Mid-Plane Plot of TREAT Half-Slotted Core with BUSTER in the Experiment Slot. 


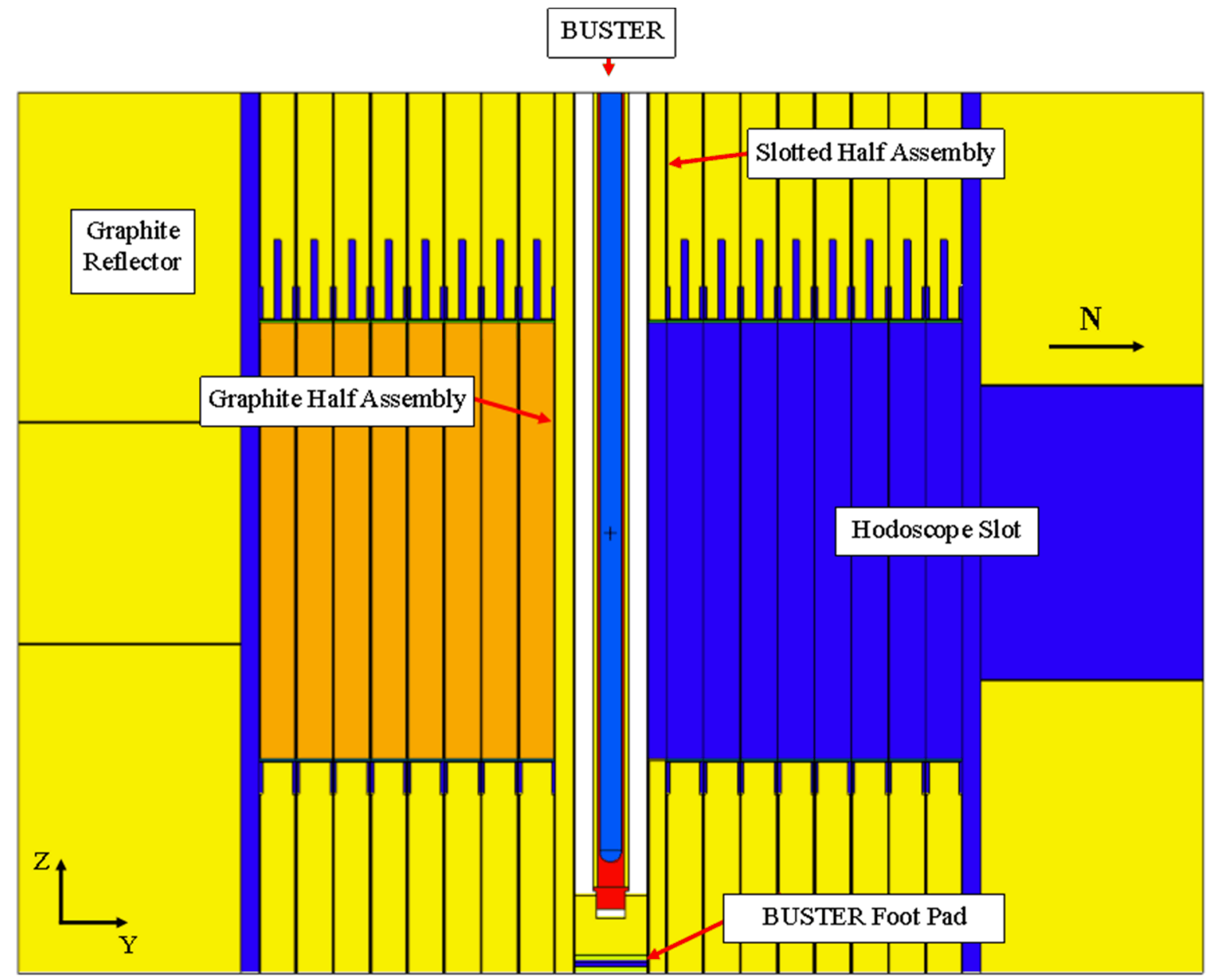

Fig. 12. Vertical Plot (YZ-Plane) of BUSTER Loaded into the TREAT Experiment Slot for the HalfSlotted Core Conguration.

Most calculations were performed with the models at room temperature: $\sim 300 \mathrm{~K}$. Transient testing in TREAT would typically encompass temperatures ranging between $\sim 300 \mathrm{~K}$ and $\sim 900 \mathrm{~K}$; however, power distributions axially and radially throughout the core strongly depend upon core/assembly arrangement optimization and operational aspects of the integrated control systems (Bess et al., 2018), such as shown in the example peak-to-average power peaking distribution per assembly, is shown in Fig. 13. In addition, these calculations were performed at steady-state, not under transient 
conditions, with $\mathrm{k}_{\mathrm{eff}}$ made as near critical as possible by insertion of the control/shutdown rods. During a transient test in TREAT, the transient will initiate from critical, and undergo supercritical and subcritical conditions at elevated powers and temperatures prior to termination. Historic calculations served only for course refinement of test parameters, with numerous transient calibration tests utilized to verify test performance characteristics (Robinson and Bauer 1994). The desire to implement advanced modeling and simulation capabilities today to provide 3-D modeling and simulation of TREAT operations and experimentation is an ongoing process that can significantly reduce the quantity of required experimental validation tests (DeHart et al., 2016).

The calculations provided herein provide baseline reference values within BUSTER for a typical half- and full-slotted TREAT core layout. These values provide results adequate for design scoping analysis. More detailed analyses of specific test designs coupled with given core/assembly layouts and reactivity control specifications should be performed where higher fidelity results are required. Current nuclear characterizations computed within BUSTER include neutron and photon fluxes, displacements per atom, and wire heating rates, as discussed more thoroughly below. Future characterization studies to provide a more comprehensive experiment-design testbed platform will also be briefly discussed. 


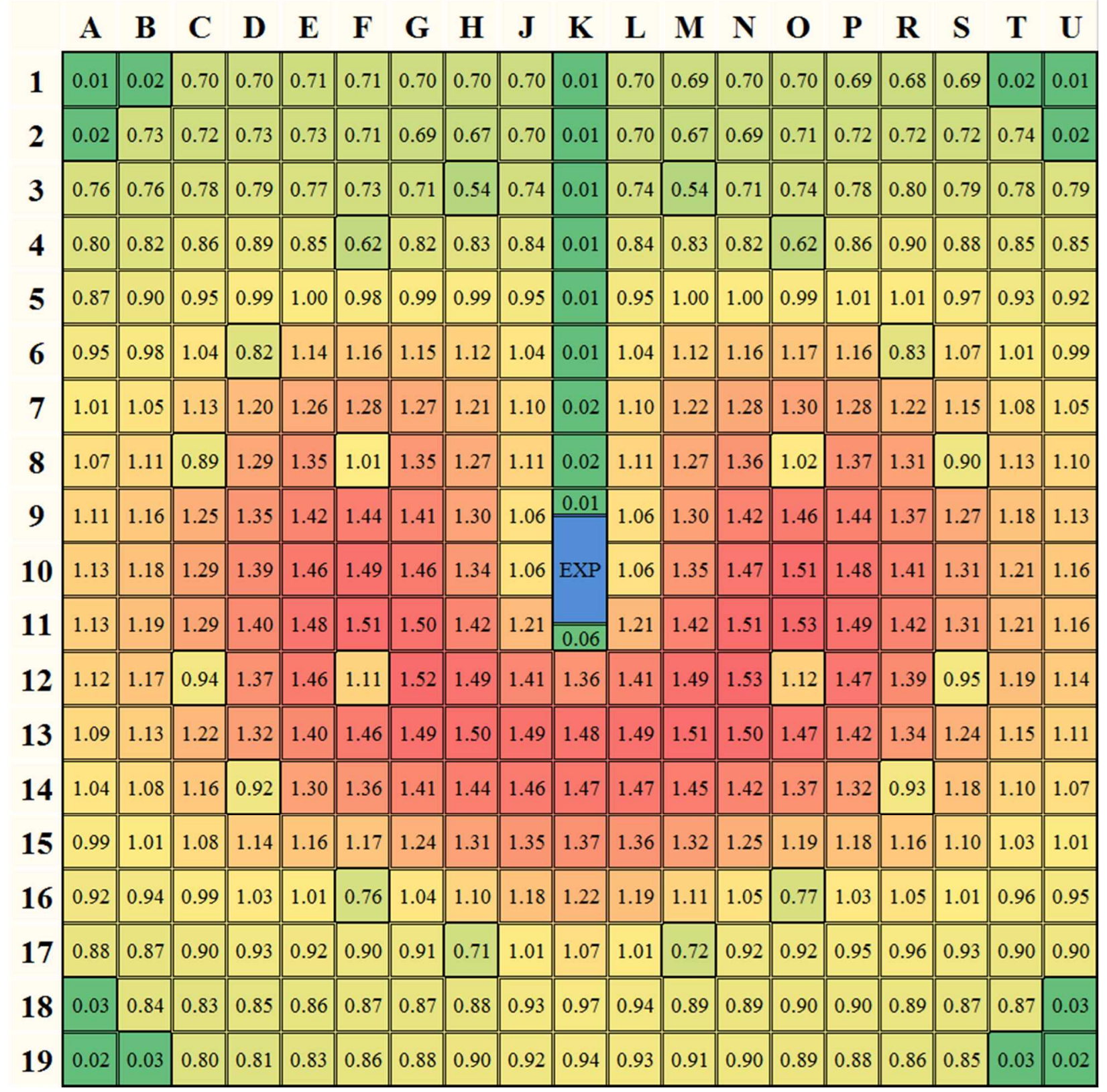

Fig. 13. Example Peak-to-Average Power Peaking Distribution for a Half-Slotted Core Loading.

\subsection{Flux Calculations}

Neutron and photon flux calculations were computed for both half- and full-slotted cores at isothermal temperatures of $300 \mathrm{~K}, 600 \mathrm{~K}$, and $1200 \mathrm{~K}$ using standard nuclear data libraries provided 
with MCNP. Standard MCNP type F4 flux tallies, which is a track length estimate for a cell flux (X-5 Monte Carlo Team 2014), were applied axially along BUSTER with output results provided in units of $\mathrm{n} / \mathrm{cm}^{2 \cdot} \mathrm{s}_{\mathrm{p}}$, where $\mathrm{s}_{\mathrm{p}}$ indicates the flux is per neutron source particle, or fission neutrons, in the reactor. The number of fission neutrons is computed using Eq. (1) (Lamarsh 1966):

$$
\text { Fission Rate }\left(\frac{\text { neutrons }}{M W \cdot S}\right)=s_{p}=\frac{\eta}{E_{R}}\left(\frac{1}{M e V}\right) \times\left(\frac{10^{6} J}{M W \cdot S}\right) \times\left(\frac{M e V}{1.60219 \times 10^{-13} \mathrm{~J}}\right) \text {, }
$$

where $\eta$ is the average number of neutrons produced per neutron absorbed, 2.437 in this analysis; and $E_{R}$ is the average recoverable energy released per fission, $199.954 \mathrm{MeV}$ in this analysis.

A delayed energy value of $\sim 200 \mathrm{MeV}$ accounts for total energy released by fission products, neutrons, prompt photons, captured photons, delayed photons, and delayed betas. A prompt energy value of $180.65 \mathrm{MeV}$, accounting solely for fission products, neutrons, and prompt photons, could instead be used, similar to a value of $182 \mathrm{MeV}$ applied elsewhere (DeHart et al., 2017), depending on the focus and application of the analysis; which would result in approximately a $10 \%$ increase in absolute flux values. The fission rate conversion factor changes the tallied flux results into units of $\mathrm{n} / \mathrm{cm}^{2} \bullet \mathrm{MW} \bullet \mathrm{s}$, or $\mathrm{n} / \mathrm{cm}^{2} \bullet \mathrm{MJ}$. The flux results tabulated herein can then be scaled according to the desired TREAT total core power or integrated energy, respectively.

The flux tallies were computed within a multigroup energy structure of 252 groups. The group structure was obtained from the SCALE Code System (Rearden and Jessee 2017). This energy group structure was selected to allow for future experiment design analyses using capabilities available in SCALE such as radioactive source term characterization activation, for the analysis of experiment instrumentation and materials within BUSTER. Neutron flux results are then plotted in subsequent 
figure as neutron flux per unit lethargy (units of $\mathrm{n} / \mathrm{cm}^{2} \bullet \mathrm{MW} \bullet \mathrm{s}$, or $\mathrm{n} / \mathrm{cm}^{2} \bullet \mathrm{MJ}$ ) versus energy for the best visualization of relative neutron energies (Greenwood 1993). The photon fluxes are plotted directly against photon energies.

\subsection{DPA Calculations}

Radiation damage in DPA was calculated using the methodology outlined in ASTM E693-17 for iron and steels (ASTM 2017) following a computational approach similar to that prescribed for Monte Carlo calculations of DPA in light water reactors (Read and de Oliveira 2011), for use as a comparative means between experiments performed in TREAT versus other reactor types using the NorgettRobinson-Torrens (NRT) model (Norgett et al., 1975). The NRT Model is often selected over other standard damage parameters not because of its accuracy in calculating displacements, but because it represents a consistent, physically-based damage parameter that can be utilized for comparison of different irradiation types (Olander and Motta 2017). Computation of the DPA in a material undergoing irradiation is a function of the total energy available within a material lattice, $E_{a}$, the energy required to displace an atom from its position within the material lattice, $E_{d}$, and the displacement efficiency, $\kappa$, as shown in Eq. (2):

$$
D P A\left(\frac{\text { displacements }}{\text { atom }}\right)=\kappa \frac{E_{a}}{2 E_{d}}
$$

The displacement efficiency is 0.8 (Greenwood and Smither 1985); the displacement energy values are provided in Table 2. The DPA analysis provided applies only to nuclear energy loss caused by elastic and inelastic neutron collisions, characteristic of neutron irradiation damage within metals, as 
implemented in the Lindhard model (Lindhard et al., 1963). Electronic excitations due to recoiling atoms, or electronic energy loss, are not a component of this study, nor calculation of the total dose in materials such as insulating material (Greenwood and Smither 1985). For elements not provided in Table 2, it is assumed that the average displacement energy is $40 \mathrm{eV} /$ displacement.

Table 2. Lindhard Cutoff Energy Required to Displace an Atom, $\mathrm{E}_{\mathrm{d}}(\mathrm{eV})$ (Greenwood and Smither 1985).

\begin{tabular}{|c|c|c|c|c|c|}
\hline Element & $E_{d}$ & Element & $E_{d}$ & Element & $\mathrm{E}_{\mathrm{d}}$ \\
\hline $\mathrm{H}$ & 10 & $\mathrm{Si}$ & 25 & $\mathrm{Ni}$ & 40 \\
\hline $\mathrm{He}$ & 10 & $\mathrm{P}$ & 30 & $\mathrm{Cu}$ & 40 \\
\hline $\mathrm{Li}$ & 10 & $\mathrm{~S}$ & 30 & $\mathrm{Zr}$ & 40 \\
\hline $\mathrm{Be}$ & 31 & $\mathrm{Cl}$ & 40 & $\mathrm{Nb}$ & 40 \\
\hline B & 25 & K & 40 & Mo & 60 \\
\hline $\mathrm{C}$ & 31 & $\mathrm{Ca}$ & 40 & $\mathrm{Ag}$ & 60 \\
\hline $\mathrm{N}$ & 30 & $\mathrm{Ti}$ & 40 & $\mathrm{Ta}$ & 53 \\
\hline $\mathrm{O}$ & 30 & V & 40 & W & 90 \\
\hline $\mathrm{F}$ & 30 & $\mathrm{Cr}$ & 40 & $\mathrm{Au}$ & 30 \\
\hline $\mathrm{Na}$ & 25 & $\mathrm{Mn}$ & 40 & $\mathrm{~Pb}$ & 25 \\
\hline $\mathrm{Mg}$ & 25 & $\mathrm{Fe}$ & 40 & Other* & 40 \\
\hline $\mathrm{Al}$ & 27 & Co & 40 & & \\
\hline
\end{tabular}

*Assumed nominal value in this analysis for elements not provided in original reference.

The total available damage energy is calculated using MCNP with ENDF/B-VII.1 nuclear data libraries. The damage energy production cross sections obtained via the HEATR module of NJOY (MacFarlane and Muir 1994) are available in MCNP for ENDF/B-VII.1, but not for ENDL92 (hence no DPA calculations for neon and platinum). Calculations were also not performed for fissionable isotopes. The neutron flux at the center of the active fuel region of the core within BUSTER is calculated using the F4:n flux tally. A tally multiplier specifier, FM4, is then applied, per material, using the damage energy production cross sections, which has the ENDF/B reaction number 444 (MacFarlane and Muir 1994, X-5 Monte Carlo Team 1994). The total available damage energy is computed, integrated across all neutron energies, as the neutron flux multiplied by the cross-section data to provide tally results in 
units of $\mathrm{MeV} \cdot$ barn/atom $\bullet \mathrm{cm}^{2} \bullet \mathrm{sp}_{\mathrm{p}}$. The fission rate in Eq.(1) is multiplied against the tally results and then that product placed into Eq.(2) for each element, including the conversion of $1 \times 10^{-24} \mathrm{~cm}^{2} / \mathrm{barn}$. The final calculated values for DPA are provided in units of DPA/MW•s, or DPA/MJ, and are provided for both half- and full-slotted core loadings. It should also be noted that these DPA calculations indicate the total initial energy available to produce damage, and not the final permanent damage (Greenwood 1993). Furthermore, a value of 1 DPA represents, on average, the complete displacement of all atoms within a given material (Zinkle and Busby 2009, Allen et al., 2017).

An athermal recombination-corrected dpa (arc-dpa) analysis is recommended to account for the overestimation of damage production, especially in metals, as the NRT model ignores recombination effects after a displacement cascade (Nordlund, et al., 2015). While the arc-dpa approach is internationally recognized for its more accurate estimate of actual damage production, it is not readily adopted nor intended to replace the traditional NRT approach (Stroller, et al., 2015). The arc-dpa values for the neutron irradiation of metals is typically expected to be $\sim 1 / 3^{\text {rd }}$ the dpa values obtained via the NRT method (Olander and Motta 2017). However, a more comprehensive approach to arc-dpa analysis can be found elsewhere (Konobeyev, et al. 2017) although it is not implemented in current efforts to more readily facilitate comparability against other nuclear reactor facilities.

\subsection{Wire Heating Rate Calculations}

Wire heating rate, $\mathrm{q}_{\text {wire, }}$ calculations were performed in MCNP by individually modeling thin 1mm-diameter "wires" of material within the active, fueled-region of the core along the axial centerline of BUSTER for both half- and full-slotted cores. The wires have a total length of $120.9675 \mathrm{~cm}(47-5 / 8$ in.). The total energy deposited (in units of $\mathrm{MeV}$ ) in the total wire volume was then computed using the 
F6 tally (X-5 Monte Carlo Team 2014). The tally results are multiplied by the first term, $\left(\eta / E_{R}\right)$ of the fission rate obtained in Eq.(1) and then multiplied by a core power of $1 \mathrm{MW}$. Because the F6 tally only accounts for energy deposition from fission products, neutrons, prompt photons, and captured photos, the tally is also multiplied by 1.0642 to account for heating contributions from delayed gamma and beta sources of $\sim 6.42 \%$ of the total energy deposition. A total correction factor of $\sim 0.013 \mathrm{MW} / \mathrm{MW} \cdot \mathrm{MeV}$ is obtained and applied to calculate the MW heating in the wire divided by total power of the core, which must be multiplied with the F6 tally result from MCNP. Division of the individual heating rates by the individual wire masses, $\mathrm{m}_{\text {wire, }}$ can be used to provide results in units of $\mathrm{W} / \mathrm{g} \bullet \mathrm{MW}$, similar to calculations of the power coupling factor (PCF) in TREAT nuclear fuel testing experiments (Robinson and Bauer 1994, DeHart et al., 2017). A summary of the mathematics behind the wire heating rate calculations is provided in Eq.(3).

$$
\text { Wire Heating Rate }\left(\frac{W}{g \cdot M W}\right)=q_{\text {wire }}=1.0642 \times \frac{F 6(\mathrm{MeV})}{m_{\text {wire }}(g)} \times \frac{\eta}{E_{R}}\left(\frac{1}{M e V}\right) \times\left(\frac{10^{6} \mathrm{~W}}{M W}\right) \text {. }
$$

An average heating rate is obtained by performing the tally analysis along the full length of each wire. A peak heating rate is also calculated for a $10-\mathrm{cm}$-long wire placed within the highest flux region of BUSTER near the center of the active core. The contribution to material heating from neutrons and photons was individually tabulated to identify key sources of heating in different in-core material and instrumentation packages. Alternatively, units of $\mathrm{J} / \mathrm{g} \bullet \mathrm{MJ}$ can be used for the wire energy deposition to allow calculations based directly on total reactor energy, convenient for finite duration, dynamic transient reactor power histories. 
To negate the effect of the selection of the application of prompt vs delayed neutrons in effecting heating rate, or PCF, tallies, the total heat deposited in TREAT can also be tallied and utilized to normalize the results per MW. Neutron and photon energy deposition in the core and permanent reflector of TREAT account for $\geq 99 \%$ of the total thermal energy in the MCNP models. The wire heating rates can then be computed via MCNP using Eq.(4).

Wire Heating Rate $\left(\frac{\mathrm{W}}{g \cdot M W}\right)=q_{\text {wire }}=\frac{1}{m_{\text {wire }}(g)} \times \frac{F 6(\mathrm{MeV})_{\text {wire }}}{F 6(\mathrm{MeV})_{\text {reactor }}} \times\left(\frac{10^{6} \mathrm{~W}}{M W}\right)$.

\section{Results and Discussion}

\subsection{Neutron Flux Calculations}

Neutron fluxes in BUSTER were computed for TREAT cores at isothermal temperatures of 300 $\mathrm{K}, 600 \mathrm{~K}$, and $1200 \mathrm{~K}$ for both half- and full-slotted configurations. Control rod positions were adjusted to provide $\mathrm{k}_{\text {eff }}$ values near critical (see Table 3). The TREAT core has insufficient excess reactivity to operate at an isothermal temperature of $1200 \mathrm{~K}$; furthermore, during normal operations, the core temperature profile is not isothermal. Results are provided and normalized to a $\mathrm{k}_{\text {eff }}$ of 1.00000 solely to facilitate visualization of trends in flux calculations.

Table 3. Computed Eigenvalues for TREAT Core Loadings with BUSTER Test Vehicle.

\begin{tabular}{|c|c|c|}
\hline $\begin{array}{c}\text { Isothermal } \\
\text { Temperature }(\mathrm{K})\end{array}$ & Core Slot & $\begin{array}{c}\text { Eigenvalue, } \\
\mathrm{k}_{\mathrm{eff}}{ }^{*}\end{array}$ \\
\hline 300 & Half & 0.99995 \\
& Full & 0.99970 \\
\hline 600 & Half & 1.00057 \\
& Full & 1.00063 \\
\hline 1200 & Half & 0.98535 \\
& Full & 0.96047 \\
\hline
\end{tabular}


${ }^{*}$ Calculated uncertainty in $\mathrm{k}_{\mathrm{eff}}$ is $\leq \pm 0.00003(1 \sigma)$

The peak fuel and clad temperature has a limiting control setting (LCS) of $\leq 600{ }^{\circ} \mathrm{C}(\sim 873 \mathrm{~K})$ during normal TREAT transient operations to maximize fuel lifetime by minimizing oxidation of the Zircaloy-3 cladding, maintaining clad integrity (TS-420 2017, SAR-420 2017). During typical transient tests the fueled region of the core is expected to be between room temperature, $\sim 300 \mathrm{~K}$, and $873 \mathrm{~K}$. The amount of excess reactivity loaded into a given core/experiment configuration is limited to prevent transient excursions at higher temperatures. The characterization transient measurements performed for the current core configuration determined that a step insertion of approximately $4.6 \% \Delta \mathrm{k} / \mathrm{k}$ is needed to achieve the temperature limit of $600{ }^{\circ} \mathrm{C}$, and approximately $5.9 \% \Delta \mathrm{k} / \mathrm{k}$ to reach a temperature of $820^{\circ} \mathrm{C}$.

The total absolute neutron flux axial profile within BUSTER is shown in Fig. 14 for calculations performed at $300 \mathrm{~K}$, comparing results from both the half- and full-slotted cores. The peak neutron flux near the core centerline is identified; it is approximately $10 \%$ greater in the half-slotted core than the full-slotted core. The neutron flux per unit lethargy is plotted in Fig. 15 for the full-slotted core at the peak flux location, positions at the top and bottom of the active core region, inside bottom of the BUSTER test vehicle, and at the top of the upper axial graphite reflectors. The neutron flux is approximately $30 \%$ thermal $(<0.625 \mathrm{eV}), 50 \%$ epithermal, and $20 \%$ fast $(>100 \mathrm{keV})$ within the main test region of the core. The neutron flux is more thermalized outside the fueled region of TREAT, as shown in Fig. 16. There is not a significant difference in the neutron flux spectra between full- and halfslotted cores (see Fig. 17).

Historical data for neutron flux measurements performed in TREAT are not available in significant supply. An experimenter's guide (Swanson 1991) reports a neutron flux for a central void in TREAT as $5 \times 10^{12} \mathrm{n} / \mathrm{cm}^{2} / \mathrm{s} / \mathrm{MW}$ (converted to units comparable with results in this study). The details 
regarding how the neutron flux was actually measured, core configuration, or even test vehicle apparatus is unknown. Furthermore, this reported neutron flux value appears in a TREAT report published nearly two decades earlier (ANL/RAS 1972), before various upgrades and configuration changes leading to the modern operational core. However, the reported value compares favorably with those calculated and provided in Fig. 14. Construction of the BUSTER test vehicle is in progress. Once completed, validation experiment measurements will be performed to determine the neutron flux for comparison against these calculations. 


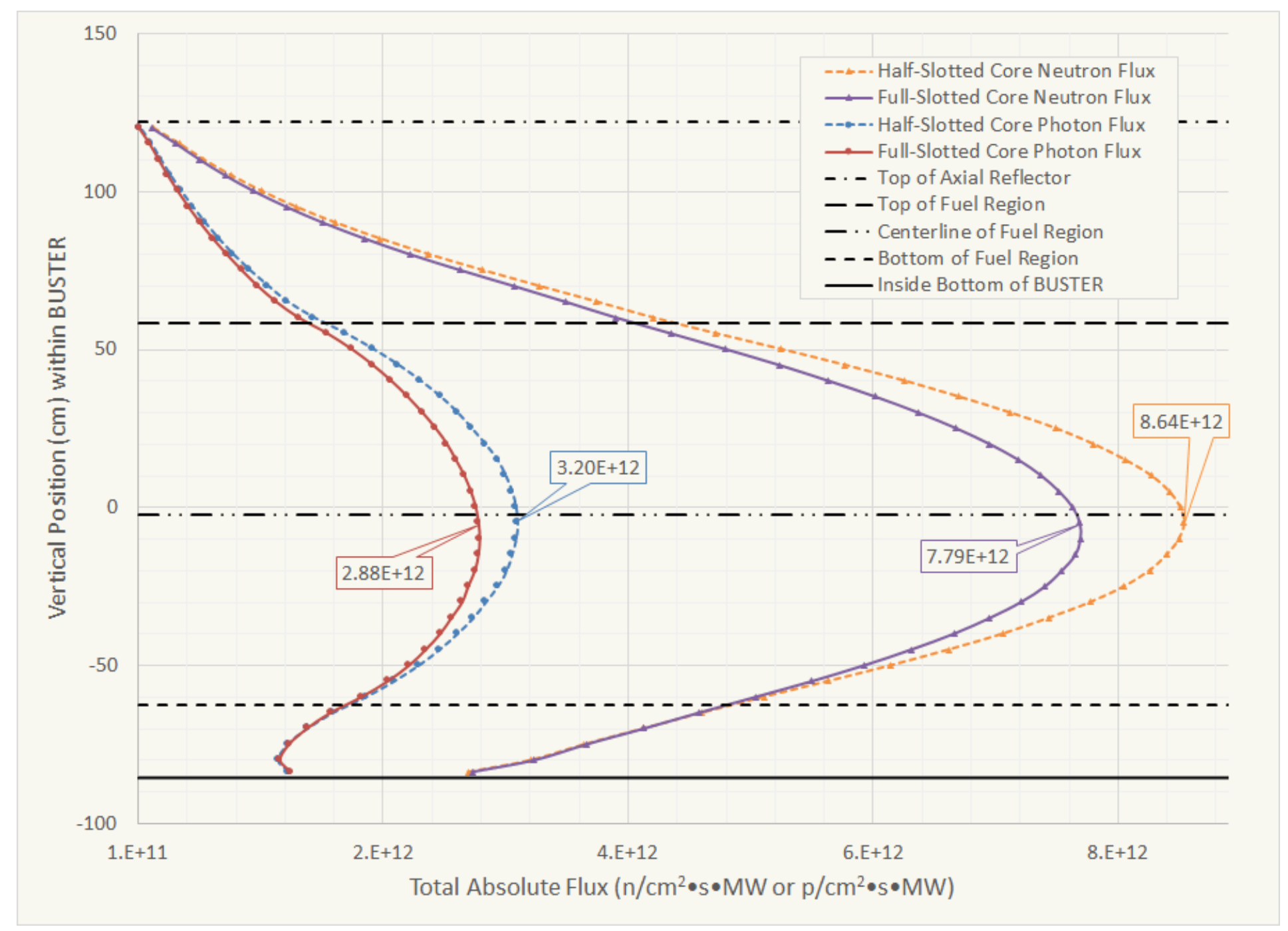

Fig. 14. Total Absolute Flux Axial Profile within BUSTER (300 K). 


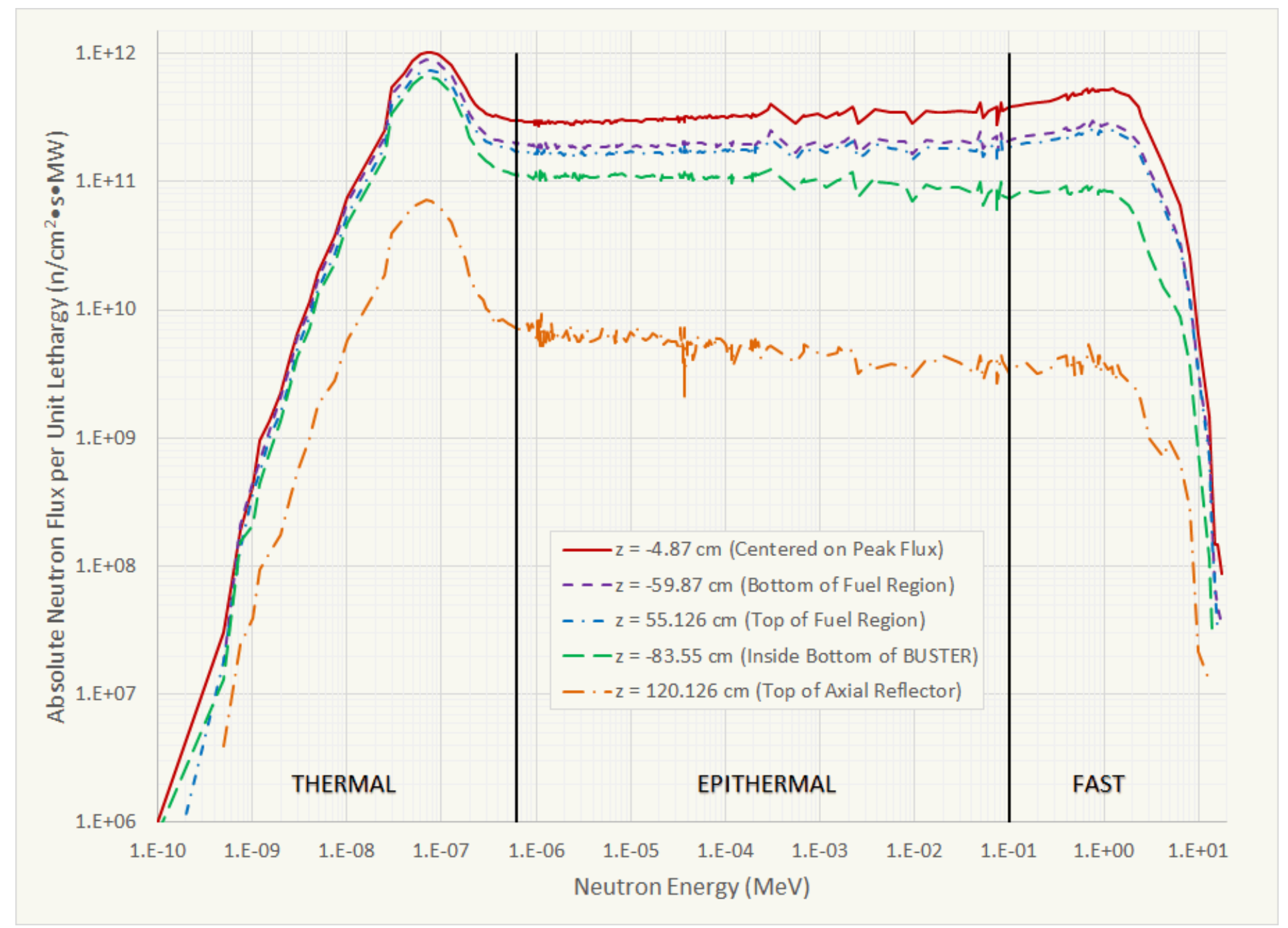

Fig. 15. Absolute Neutron Flux per Unit Lethargy Axial Spectral Distribution for Full-Slotted Core (300 K). 


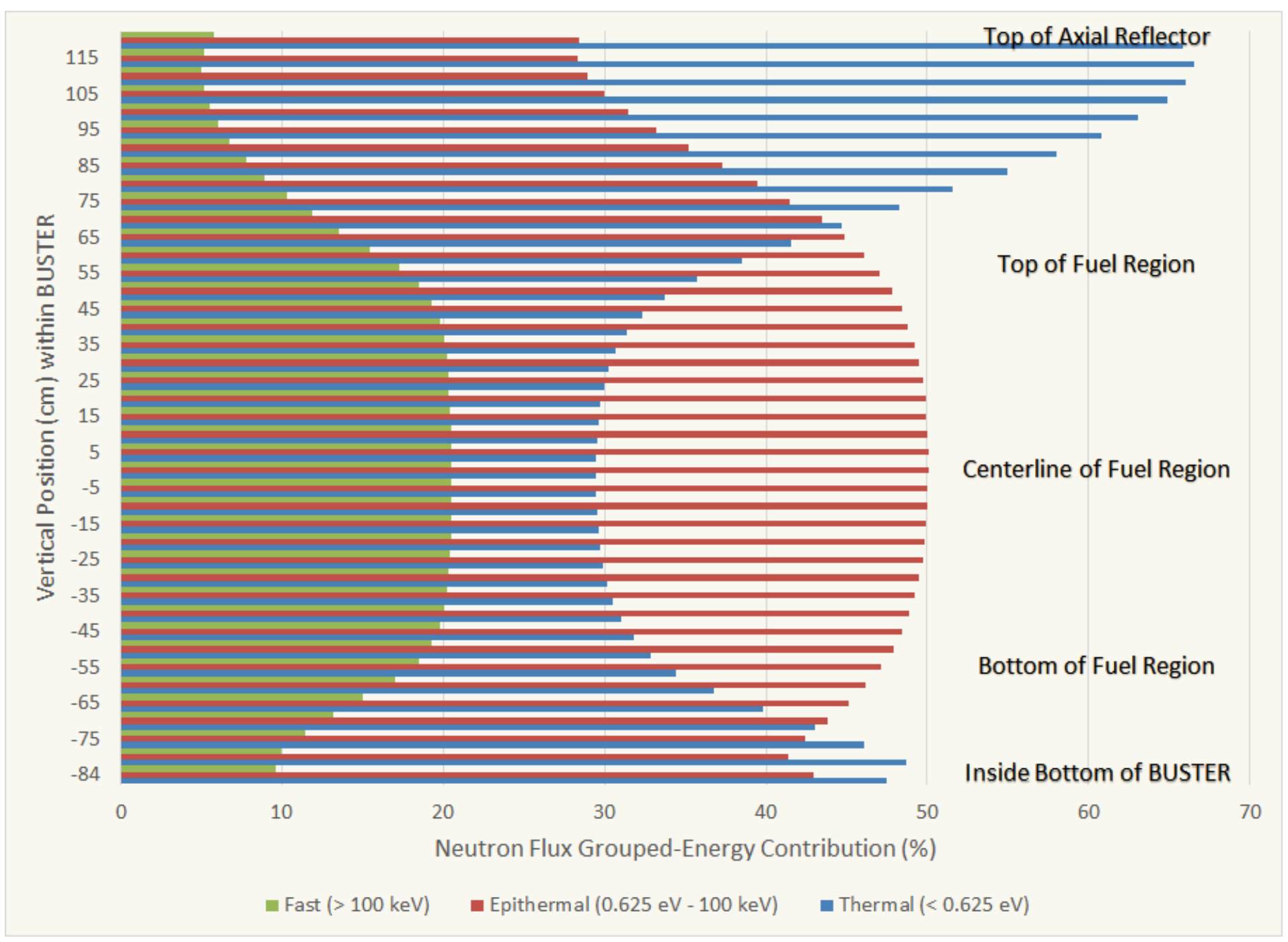

Fig. 16. Axial Distribution of Contribution to Neutron Spectra by Energy Groups for Full-Slotted Core (300 K). 


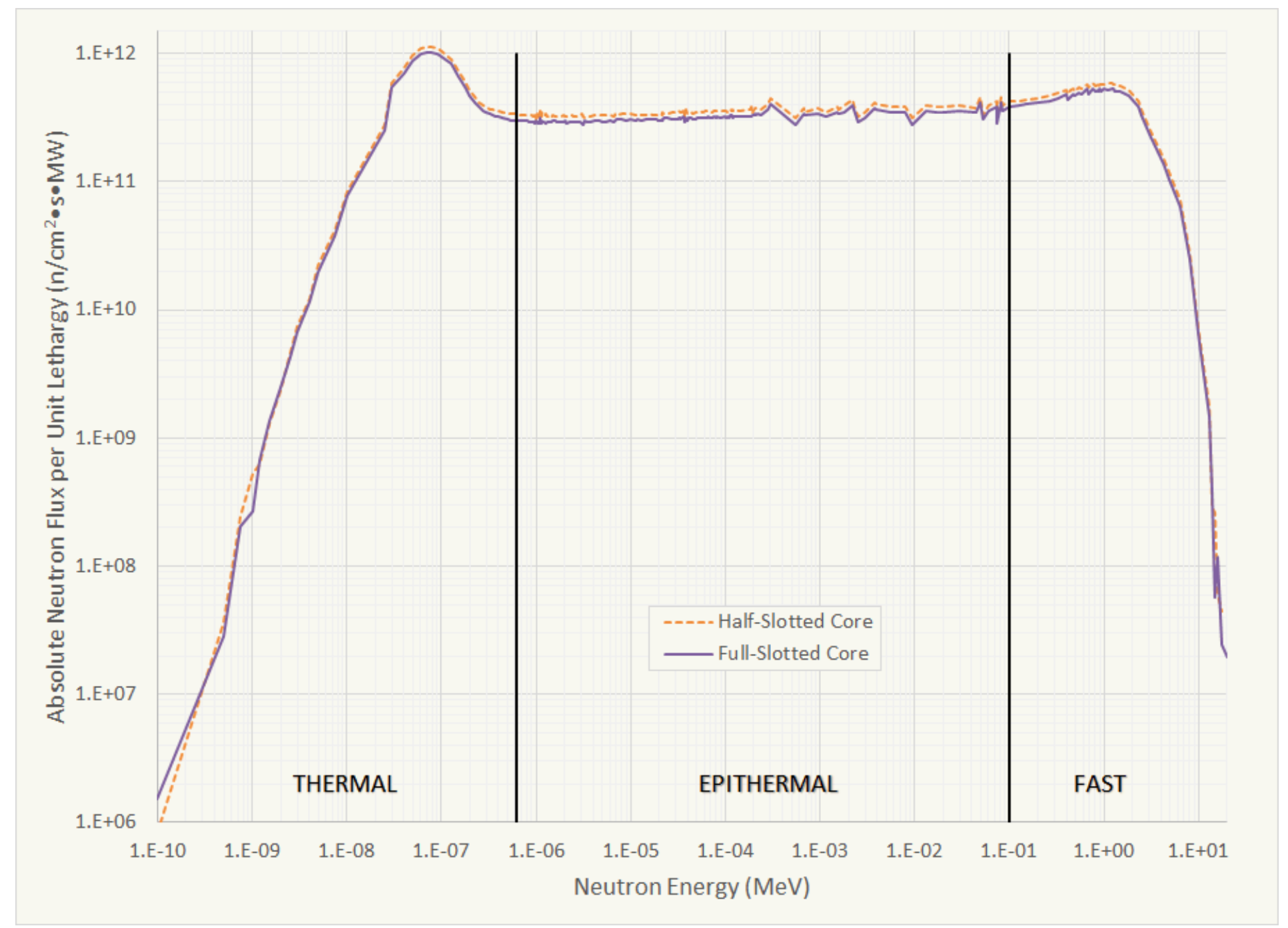

Fig. 17. Comparison of Peak Neutron Flux Spectral Distribution between Half- and Full-Slotted Cores (300 K). 
As the temperature increases in TREAT, the neutron spectrum shifts to higher energies (see Fig. 18). The effective fission rate in the core is decreased since the peak of the near Maxwellian shape is shifted from the higher interaction probability region of the $1 / v$ dependence of the ${ }^{235} \mathrm{U}$ fission cross section. Higher energy neutrons leak from the core and the total neutron flux in the core must increase to maintain criticality via an increased fission rate (see Fig. 19) by further withdrawing the control rods. Because of the additional leakage in the full-slotted core, the relative fission rate necessary to maintain criticality needs to increase more than in the half-slotted core. Therefore, the thermal neutron component of the flux in the center of the experiment contains more thermalized neutrons, leading to the increase in PCF, characterized within the measurement of the Transient Correction Factor (TCF), in historic M8CAL tests (Robinson and Bauer 1994). There is no significant difference between calculated spectra for the half- and full-slotted cores with increasing isothermal core temperatures. 


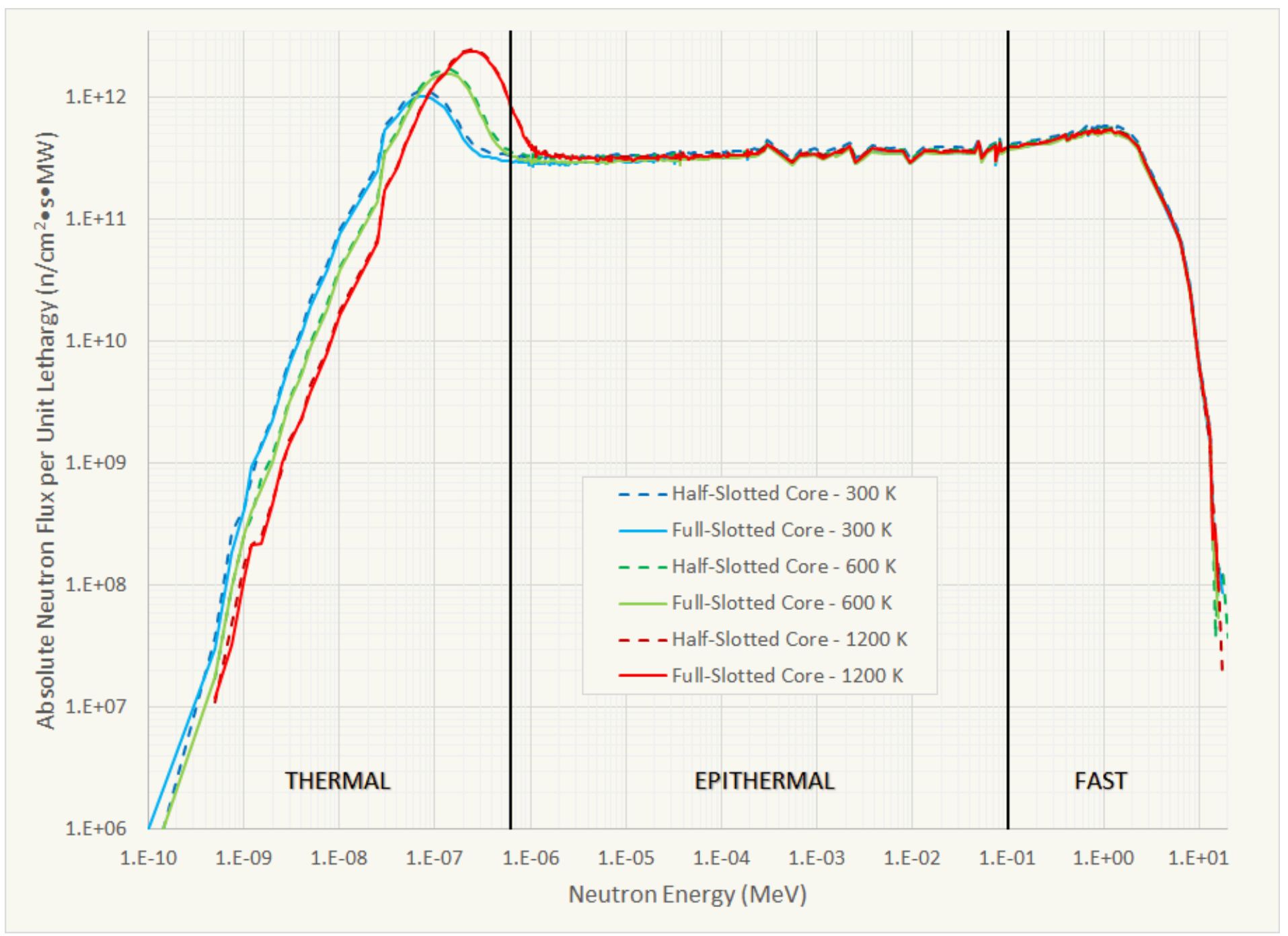

Fig. 18. Comparison of Peak Neutron Flux Spectral Distribution with Increasing Core Temperature. 


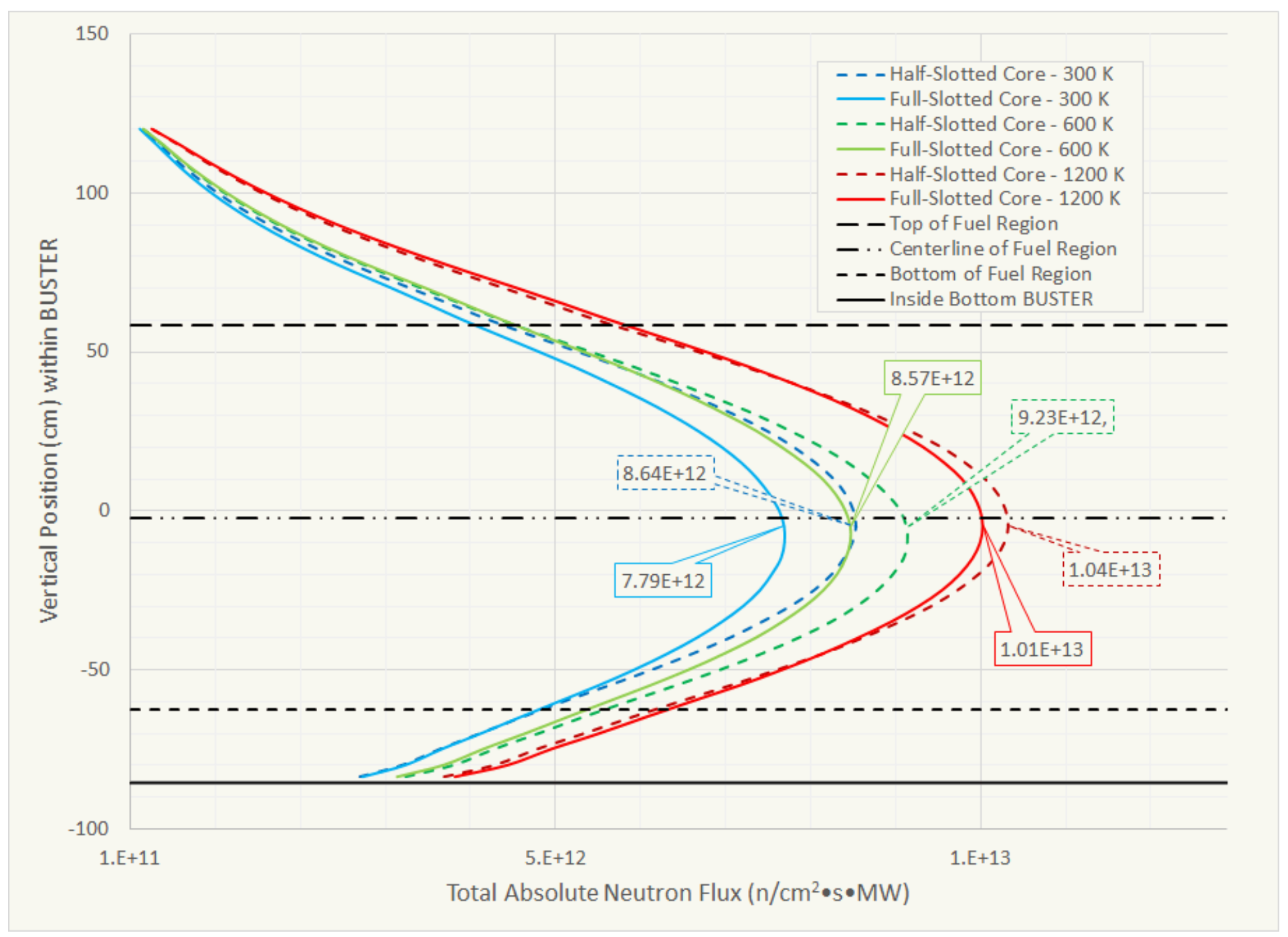

Fig. 19. Comparison of Neutron Flux Axial Profile with Increasing Core Temperatures. 


\subsection{Photon Flux Calculations}

The total absolute photon flux axial profile within BUSTER is shown in Fig. 14 for calculations performed at $300 \mathrm{~K}$, comparing results from both the half- and full-slotted cores. The absolute photon flux is approximately 2.7 times less than the neutron flux at the peak flux position in BUSTER. This flux accounts for photon transport of photons generated in the core; characterization of photons from material activation and isotopic decay was not included in the current effort. The peak photon flux near the core centerline is identified; it is approximately $10 \%$ greater in the half-slotted core than the fullslotted core. The absolute photon flux is plotted in Fig. 20 for the full-slotted core at the peak flux location, positions at the top and bottom of the active core region, inside bottom of the BUSTER test vehicle, and at the top of the upper axial graphite reflectors. Approximately $54 \%$ of the photon energies are below an arbitrarily selected threshold of $0.6 \mathrm{MeV}$ within the main test region of the core, as shown in Fig. 21; approximately $29 \%$ of the photon energies are between 0.6 and $3 \mathrm{MeV}$, with the remaining $17 \%$ above $3 \mathrm{MeV}$. There is not a significant difference in the photon spectra between full- and halfslotted cores (see Fig. 22).

Historic photon flux data is limited to a reported value of $6 \times 10^{3} \mathrm{R} / \mathrm{MJ}$ (ANL/RAS 1972 and Swanson 1991). As with the neutron flux measurement, the details regarding this measurement are completely unknown, making direct comparison against the MCNP calculations less meaningful. Modern measurements in the BUSTER test vehicle can be performed to provide validation experiment results. 


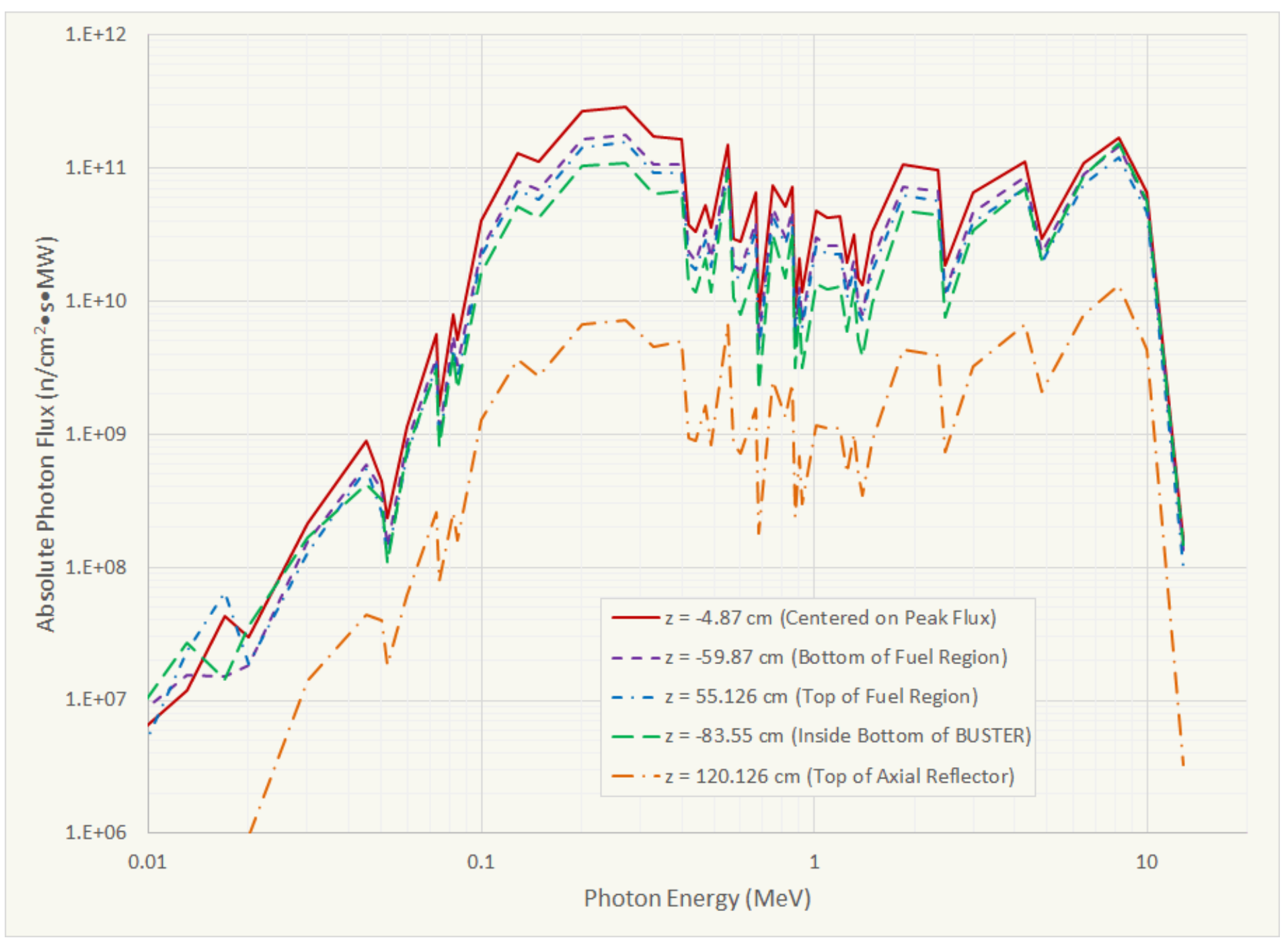

Fig. 20. Absolute Photon Flux Axial Spectral Distribution for Full-Slotted Core (300 K). 


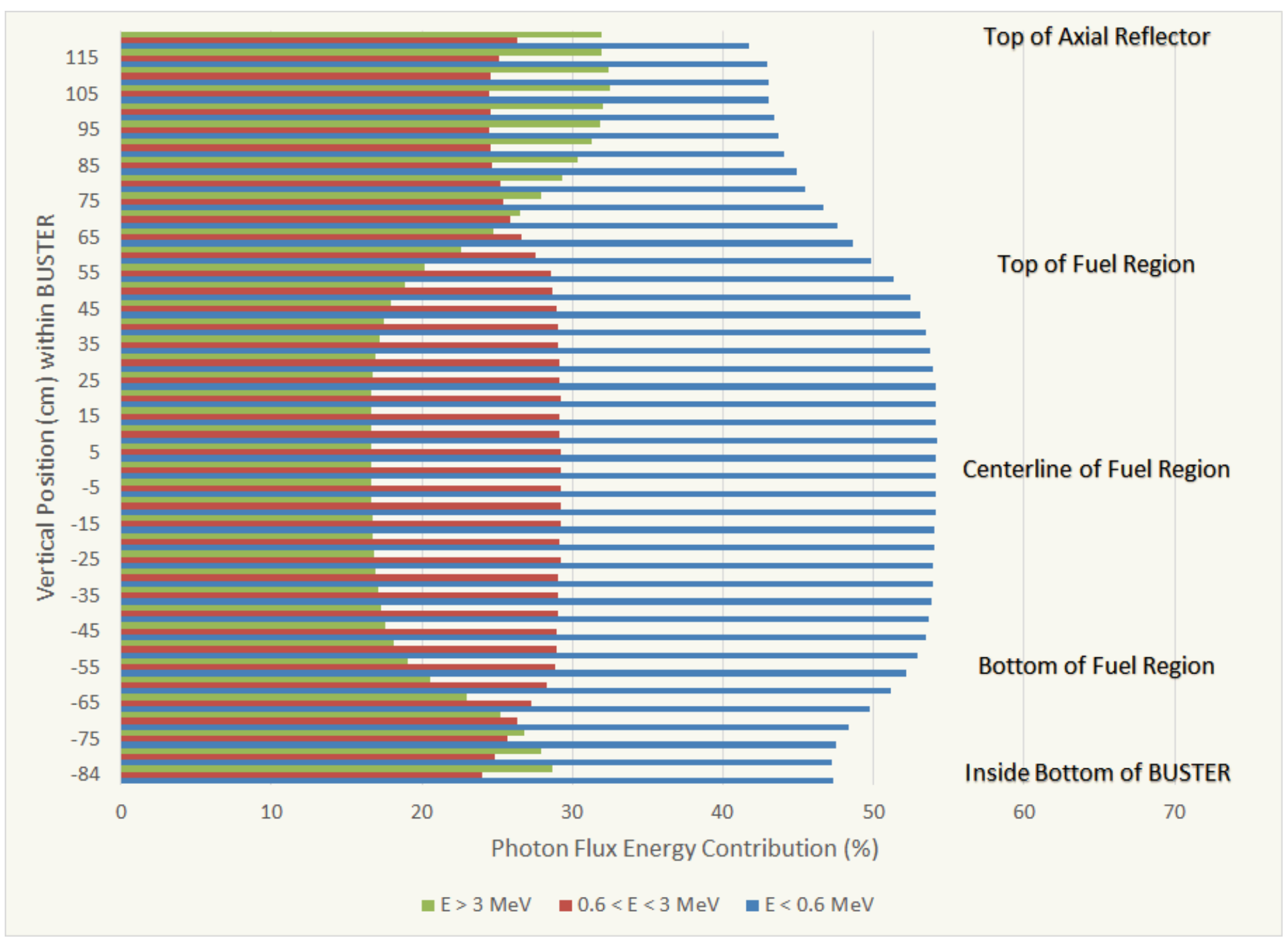

Fig. 21. Axial Distribution of Photon Spectra Relative to $1 \mathrm{MeV}$ for Full-Slotted Core (300 K). 


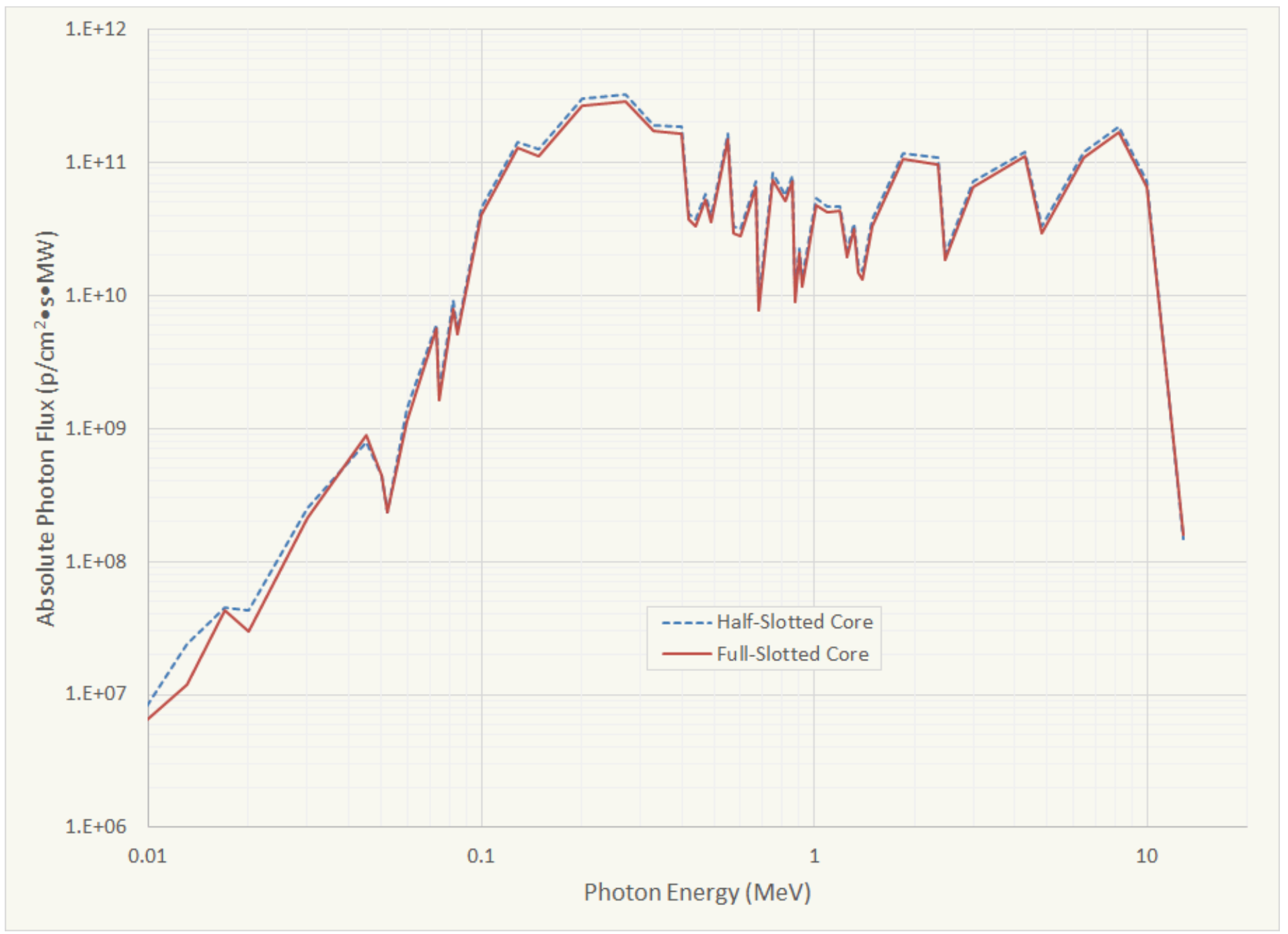

Fig. 22. Comparison of Peak Photon Flux Spectral Distribution between Half- and Full-Slotted Cores (300 K). 


\subsection{DPA Calculations}

Tabulated results for DPA calculations within the BUSTER irradiation test of TREAT are provided in Table 4. Calculations for a number of elements and isotopes are provided for comparison; the most applicable values are those computed for metallic solids, as discussed previously. Results are presented with two significant digits. The average $1 \sigma$ uncertainty is on the order of approximately 0.15

$\%$. Damage calculations in the full-slotted core are approximately $10 \%$ lower than those of the halfslotted core due to the increased fission density required for operation with a full slot. 
Table 4. DPA Calculation Results in Units of DPA/MJ $\left(\times 10^{-10}\right){ }^{*}$

\begin{tabular}{|c|c|c|c|c|c|c|c|}
\hline Material & Type $^{\dagger}$ & $\begin{array}{l}\text { Half-Slotted } \\
\text { Core }\end{array}$ & $\begin{array}{l}\text { Full-Slotted } \\
\text { Core }\end{array}$ & Material & Type $^{\dagger}$ & $\begin{array}{l}\text { Half-Slotted } \\
\text { Core }\end{array}$ & $\begin{array}{c}\text { Full-Slotted } \\
\text { Core }\end{array}$ \\
\hline $\mathrm{H}$ & $\mathrm{N}$ & 8.4 & 7.6 & Y & $\mathrm{M}$ & 11 & 9.9 \\
\hline${ }^{2} \mathrm{H}$ & $\mathrm{N}$ & 3.1 & 2.8 & $\mathrm{Zr}$ & M & 11 & 9.7 \\
\hline${ }^{3} \mathrm{H}$ & $\mathrm{N}$ & 2.1 & 1.9 & $\mathrm{Nb}$ & M & 10 & 9.2 \\
\hline $\mathrm{He}$ & $\mathrm{N}$ & 8.1 & 7.3 & Mo & M & 6.8 & 6.1 \\
\hline${ }^{3} \mathrm{He}$ & $\mathrm{N}$ & 7700 & 7000 & $\mathrm{Tc}$ & M & 9.7 & 8.7 \\
\hline $\mathrm{Li}$ & M & 320 & 290 & $\mathrm{Ru}$ & M & 9.4 & 8.5 \\
\hline${ }^{7} \mathrm{Li}$ & M & 11 & 10 & $\mathrm{Rh}$ & M & 9.6 & 8.6 \\
\hline $\mathrm{Be}$ & M & 11 & 10 & $\mathrm{Pd}$ & M & 8.8 & 7.9 \\
\hline B & D & 3600 & 3300 & $\mathrm{Ag}$ & M & 5.7 & 5.2 \\
\hline${ }^{10} \mathrm{~B}$ & D & 18000 & 16000 & $\mathrm{Cd}$ & M & 260 & 240 \\
\hline $\mathrm{C}$ & $\mathrm{N}$ & 14 & 12 & In & M & 33 & 29 \\
\hline $\mathrm{N}$ & $\mathrm{N}$ & 21 & 19 & $\mathrm{Sn}$ & M & 7.4 & 6.7 \\
\hline $\mathrm{O}$ & $\mathrm{N}$ & 19 & 17 & $\mathrm{Sb}$ & D & 8.4 & 7.6 \\
\hline $\mathrm{F}$ & $\mathrm{N}$ & 25 & 23 & $\mathrm{Te}$ & D & 8.1 & 7.3 \\
\hline $\mathrm{Na}$ & M & 24 & 21 & I & $\mathrm{N}$ & 7.5 & 6.8 \\
\hline $\mathrm{Mg}$ & M & 29 & 26 & $\mathrm{Xe}$ & $\mathrm{N}$ & 8.4 & 7.5 \\
\hline $\mathrm{Al}$ & M & 21 & 19 & Cs & M & 7.3 & 6.6 \\
\hline $\mathrm{Si}$ & $\mathrm{D}$ & 22 & 20 & $\mathrm{Ba}$ & M & 7.6 & 6.8 \\
\hline $\mathrm{P}$ & $\mathrm{N}$ & 16 & 14 & $\mathrm{La}$ & M & 7.4 & 6.7 \\
\hline $\mathrm{S}$ & $\mathrm{N}$ & 15 & 14 & $\mathrm{Ce}$ & M & 7.4 & 6.7 \\
\hline $\mathrm{Cl}$ & $\mathrm{N}$ & 13 & 12 & $\operatorname{Pr}$ & M & 7.5 & 6.7 \\
\hline $\mathrm{Ar}$ & $\mathrm{N}$ & 11 & 10 & $\mathrm{Nd}$ & M & 7.8 & 7.0 \\
\hline $\mathrm{K}$ & M & 10 & 9.0 & $\mathrm{Sm}$ & M & 20 & 18 \\
\hline $\mathrm{Ca}$ & M & 10 & 9.2 & $\mathrm{Eu}$ & M & 100 & 91 \\
\hline $\mathrm{Sc}$ & M & 14 & 12 & $\mathrm{Gd}$ & M & 110 & 99 \\
\hline $\mathrm{Ti}$ & M & 12 & 11 & $\mathrm{~Tb}$ & M & 8.4 & 7.6 \\
\hline $\mathrm{V}$ & M & 14 & 13 & Dy & M & 8.4 & 7.6 \\
\hline $\mathrm{Cr}$ & M & 11 & 9.7 & Но & M & 7.4 & 6.7 \\
\hline $\mathrm{Mn}$ & M & 11 & 10 & $\mathrm{Er}$ & M & 8.8 & 7.9 \\
\hline $\mathrm{Fe}$ & M & 9.4 & 8.5 & $\mathrm{Tm}$ & M & 7.4 & 6.6 \\
\hline Co & $\mathrm{M}$ & 14 & 13 & $\mathrm{Lu}$ & $\mathrm{M}$ & 13 & 12 \\
\hline $\mathrm{Ni}$ & $\mathrm{M}$ & 12 & 11 & $\mathrm{Hf}$ & M & 8.7 & 7.8 \\
\hline $\mathrm{Cu}$ & $\mathrm{M}$ & 10 & 9.4 & $\mathrm{Ta}$ & M & 4.8 & 4.3 \\
\hline $\mathrm{Zn}$ & M & 11 & 10 & W & M & 2.4 & 2.2 \\
\hline $\mathrm{Ga}$ & $\mathrm{M}$ & 10 & 9.5 & $\operatorname{Re}$ & $\mathrm{M}$ & 6.7 & 6.0 \\
\hline $\mathrm{Ge}$ & $\mathrm{D}$ & 10 & 9.4 & $\mathrm{Ir}$ & $\mathrm{M}$ & 6.7 & 6.1 \\
\hline As & D & 11 & 10 & $\mathrm{Au}$ & $M$ & 13 & 11 \\
\hline $\mathrm{Se}$ & $\mathrm{N}$ & 12 & 11 & $\mathrm{Hg}$ & $\mathrm{M}$ & 9.6 & 8.7 \\
\hline $\mathrm{Br}$ & $\mathrm{N}$ & 12 & 11 & $\mathrm{Tl}$ & $\mathrm{M}$ & 5.7 & 5.2 \\
\hline $\mathrm{Kr}$ & $\mathrm{N}$ & 14 & 13 & $\mathrm{~Pb}$ & M & 9.2 & 8.3 \\
\hline $\mathrm{Rb}$ & M & 11 & 9.5 & $\mathrm{Bi}$ & $\mathrm{M}$ & 6.2 & 5.6 \\
\hline $\mathrm{Sr}$ & M & 12 & 11 & & & & \\
\hline
\end{tabular}

${ }^{*}$ Results rounded to two significant digits; the average $1 \sigma$ uncertainty in the calculated results is $\sim 0.15$ $\%$.

${ }^{\dagger}$ DPA analysis performed as if all materials were metal. This column indicates whether a material is typically considered as metal (M), metalloid (D), or nonmetal (N). 
Historic tests in TREAT have achieved peak powers of approximately 20,000 MW; however, due to the transient nature of these experiments, the maximum integrated energy remains under 3,000 MJ. Assuming a nominal value of $1 \times 10^{-9} \mathrm{DPA} / \mathrm{MJ}$, at most TREAT could deliver $3 \times 10^{-6} \mathrm{DPA} /$ test. Even assuming a delivery of 50 transient tests per year would increase that value to $1.5 \times 10^{-4} \mathrm{DPA} / \mathrm{y}$. A maximum steady-state operation of approximately $120 \mathrm{~kW}$, which is an imposed limitation to reduce radiation fields within an occupied building, only provides a nominal $1.2 \times 10^{-10} \mathrm{DPA} / \mathrm{s}$. The displacement doses in TREAT are negligible in magnitude when compared to other research, test, and prototype nuclear reactors due to the relatively short, single operation duration beyond $120 \mathrm{~kW}$ steadystate power; a sample listing is provided in Table 5. The displacement doses in TREAT are also negligible compared with lifetime doses expected in various power reactors, as listed in Table 6 . While TREAT may not provide the neutron damage capability encountered in traditional steady-state reactors, its strength is in its unique capability to provide sufficient nuclear energy during transient excursions of milliseconds to several minutes simulating off-normal, accidental, and upset conditions that represent power-cooling mismatches encountered in other nuclear reactors (Woolstenhulme et al., 2016). Thus, experiment test requirements should be compared with the capability of the reactor. A general description of simplified instrument testing is provided in Section 1.3. Typically, transient testing of nuclear materials subjected to chronic neutron exposure effects would be accomplished first by irradiating in other test reactor or commercial reactor environments to obtain the desired chronic neutron exposure effects prior to being subjected to TREAT transient irradiation testing. 
Table 5. Reference Neutron-Induced Displacement Dose Rates in Research Reactors (Klueh and Harries 2001).

\begin{tabular}{|c|c|c|c|c|}
\hline \multirow{2}{*}{ Reactor Type } & \multirow{2}{*}{$\begin{array}{l}\text { Reactor } \\
\text { Location }\end{array}$} & \multirow{2}{*}{$\begin{array}{l}\text { Facility } \\
\text { Name }\end{array}$} & \multicolumn{2}{|c|}{ Displacement Dose Rate } \\
\hline & & & $\mathrm{DPA} / \mathrm{s}$ & $\mathrm{DPA} / \mathrm{y}$ \\
\hline \multirow[t]{9}{*}{$\begin{array}{l}\text { Mixed Spectrum } \\
\text { Fission Reactor }\end{array}$} & $\begin{array}{c}\text { Mol, } \\
\text { Belgium }\end{array}$ & BR2 & $\begin{array}{c}4 \times 10^{-7} \\
\text { (core center) }\end{array}$ & 6 \\
\hline & $\begin{array}{l}\text { Petten, } \\
\text { Holland }\end{array}$ & HFR & $\begin{array}{l}2.3-2.8 \times 10^{-7} \\
(\text { high flux })\end{array}$ & $5.9-6.7$ \\
\hline & $\begin{array}{l}\text { Studsvik, } \\
\text { Sweden }\end{array}$ & R2 & $\begin{array}{c}2.5 \times 10^{-7} \\
\text { (core center) } \\
8 \times 10^{-8} \\
(\text { core edge) }\end{array}$ & $\begin{array}{c}4 \\
1.2\end{array}$ \\
\hline & $\begin{array}{l}\text { Oarai, } \\
\text { Japan }\end{array}$ & JMTR & $\begin{array}{c}3 \times 10^{-7} \\
\text { (fuel position) } \\
8 \times 10^{-8} \\
\text { (reflector position) }\end{array}$ & $\begin{array}{l}2.7 \\
0.7\end{array}$ \\
\hline & $\begin{array}{l}\text { Tokai, } \\
\text { Japan }\end{array}$ & JRR-3 & $2 \times 10^{-7}$ & 1.4 \\
\hline & $\begin{array}{l}\text { Oak Ridge, } \\
\text { Tennessee }\end{array}$ & ORR & $\begin{array}{c}3.5 \times 10^{-7} \\
2.3 \times 10^{-7}(\text { Maziasz } 1993)\end{array}$ & 11 \\
\hline & & HFIR & $\begin{array}{c}1.1 \times 10^{-7} \\
1.0 \times 10^{-6}(\text { Maziasz } 1993)\end{array}$ & $\begin{array}{c}35 \\
14 \text { (Youinou 2017) }\end{array}$ \\
\hline & $\begin{array}{l}\text { Idaho Falls, } \\
\text { Idaho }\end{array}$ & ATR & 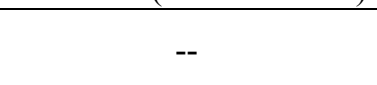 & $\begin{array}{c}6-10 \\
\text { (Youinou 2017) }\end{array}$ \\
\hline & $\begin{array}{l}\text { Cadarache, } \\
\text { France }\end{array}$ & JHR & -- & $\begin{array}{c}9-16 \\
\text { (Youinou 2017) }\end{array}$ \\
\hline \multirow[t]{6}{*}{$\begin{array}{l}\text { Fast Fission } \\
\text { Reactor }\end{array}$} & $\begin{array}{l}\text { Marcoule, } \\
\text { France }\end{array}$ & PHÉNIX & $\begin{array}{c}1.8 \times 10^{-6} \\
\text { (core center) }\end{array}$ & $e^{2}$ \\
\hline & $\begin{array}{l}\text { Dounreay, } \\
\text { UK }\end{array}$ & PFR & $\begin{array}{c}1.3 \times 10^{-6} \\
(\text { DMSA position) }\end{array}$ & -- \\
\hline & $\begin{array}{l}\text { Oarai, } \\
\text { Japan }\end{array}$ & JOYO & $\begin{array}{c}3 \times 10^{-6} \\
\text { (Mark II Core } 1^{\text {st }} \text { Grid) }\end{array}$ & 21 \\
\hline & $\begin{array}{l}\text { Idaho Falls, } \\
\text { Idaho }\end{array}$ & EBR-II & $1.2 \times 10^{-6}$ & 11 \\
\hline & $\begin{array}{c}\text { Hanford, } \\
\text { Washington }\end{array}$ & FFTF & $\begin{array}{c}1.3 \times 10^{-7} \\
1.8 \times 10^{-6}(\text { Maziasz 1993) }\end{array}$ & 41 \\
\hline & $\begin{array}{c}\text { Dimitrovgrad, } \\
\text { Russia }\end{array}$ & BOR-60 & -- & $\begin{array}{c}\sim 50 \\
\text { (Youinou 2017) }\end{array}$ \\
\hline
\end{tabular}


Table 6. Reference Neutron-Induced Displacement Doses in Fission and Fusion Energy Systems.

\begin{tabular}{|c|c|c|}
\hline $\begin{array}{c}\text { Reactor } \\
\text { Type }\end{array}$ & $\begin{array}{c}\text { Lifetime Dose, } \\
\text { DPA (Zinkle and Busby 2009) }\end{array}$ & $\begin{array}{c}\text { Maximum Dose, } \\
\text { DPA (Allen et al., 2010) }\end{array}$ \\
\hline Gen-II LWR & $\sim 5-50$ & 100 (PWR) \\
Gen-IV VHTR & $\sim 5-30$ & $1-10$ \\
Gen-IV SCWR & $\sim 10-45$ & $15-67$ \\
Gen-IV GFR & $\sim 50-85$ & 200 \\
Gen-IV LFR & $\sim 50-135$ & 200 \\
Gen-IV SFR & $\sim 90-160$ & 200 \\
Gen-IV MSR & $\sim 100-180$ & 200 \\
Fusion & $\sim 150-200$ & -- \\
\hline
\end{tabular}

${ }^{*}$ LWR $=$ Light Water Reactor, PWR $=$ Pressurized Water Reactor, VHTR $=$ Very High Temperature Reactor, SCWR $=$ Supercritical Water-cooled Reactor, GFR $=$ Gas-cooled Fast Reactor, LFR $=$ Leadcooled Fast Reactor, SFR = Sodium-cooled Fast Reactor, and MSR = Molten Salt Reactor.

\subsection{Wire Heating Rate Calculations}

Results from the wire heating rate calculations are provided in Table 7 for the half-slotted core and Table 8 for the full-slotted core. Results are presented with two significant digits. The average $1 \sigma$ uncertainty is on the order of approximately $1.1 \%$ and $0.35 \%$, respectively, for the maximum and average heating rates. Heating rate calculations in the full-slotted core are approximately $10 \%$ lower than those of the half-slotted core for the maximum rates and approximately $8 \%$ lower for the average rates. The percentage contribution to the total heating rate by neutrons or photons is also included in both tables. As expected, the heating rates are greater in materials with higher neutron absorption or fission cross sections. On average the maximum heating rates are approximately $16 \%$ greater than the average heating rates for the half-slotted core, and $14 \%$ in the full-slotted core. 
Table 7. Wire Heating Rate Calculation Results for the Half-Slotted Core in Units of W/g・MW.

\begin{tabular}{|c|c|c|c|c|c|c|c|c|c|}
\hline Material & Maximum & Average & $\% \mathrm{n}$ & $\% \mathrm{p}$ & Material & Maximum & Average & $\% \mathrm{n}$ & $\% \mathrm{p}$ \\
\hline $\mathrm{H}$ & 0.40 & 0.33 & 92.5 & 7.5 & Mo & 0.027 & 0.023 & 3.7 & 96.3 \\
\hline${ }^{2} \mathrm{H}$ & 0.13 & 0.11 & 88.4 & 11.6 & $\mathrm{Tc}$ & 0.035 & 0.030 & 0.4 & 99.6 \\
\hline${ }^{3} \mathrm{H}$ & 0.060 & 0.050 & 83.4 & 16.6 & $\mathrm{Ru}$ & 0.12 & 0.10 & 77.5 & 22.5 \\
\hline $\mathrm{He}$ & 0.062 & 0.052 & 75.8 & 24.2 & $\mathrm{Rh}$ & 0.065 & 0.056 & 0.2 & 99.8 \\
\hline${ }^{3} \mathrm{He}$ & 260.00 & 230.00 & 100.0 & 0.0 & $\mathrm{Pd}$ & 0.031 & 0.026 & 0.4 & 99.6 \\
\hline $\mathrm{Li}$ & 8.2 & 7.3 & 99.8 & 0.2 & $\mathrm{Ag}$ & 0.046 & 0.040 & 0.3 & 99.7 \\
\hline${ }^{7} \mathrm{Li}$ & 0.023 & 0.019 & 43.4 & 56.6 & $\mathrm{Cd}$ & 4.7 & 4.1 & 99.4 & 0.6 \\
\hline $\mathrm{Be}$ & 0.023 & 0.019 & 40.9 & 59.1 & In & 2.3 & 2.0 & 98.7 & 1.3 \\
\hline B & 5.9 & 5.1 & 99.7 & 0.3 & $\mathrm{Sn}$ & 0.050 & 0.043 & 41.2 & 58.8 \\
\hline${ }^{10} \mathrm{~B}$ & 8.0 & 6.8 & 99.7 & 0.3 & $\mathrm{Sb}$ & 0.22 & 0.19 & 86.4 & 13.6 \\
\hline $\mathrm{C}$ & 0.020 & 0.017 & 23.4 & 76.6 & $\mathrm{Te}$ & 0.19 & 0.16 & 83.8 & 16.2 \\
\hline $\mathrm{N}$ & 0.036 & 0.031 & 57.3 & 42.7 & I & 0.036 & 0.030 & 0.2 & 99.8 \\
\hline $\mathrm{O}$ & 0.019 & 0.016 & 16.1 & 83.9 & $\mathrm{Xe}$ & 0.28 & 0.24 & 88.3 & 11.7 \\
\hline $\mathrm{F}$ & 0.018 & 0.015 & 15.7 & 84.3 & Cs & 0.036 & 0.031 & 0.2 & 99.8 \\
\hline $\mathrm{Ne}$ & 0.018 & 0.015 & 10.5 & 89.5 & $\mathrm{Ba}$ & 0.066 & 0.055 & 47.2 & 52.8 \\
\hline $\mathrm{Na}$ & 0.017 & 0.015 & 8.1 & 91.9 & $\mathrm{La}$ & 0.10 & 0.091 & 68.3 & 31.7 \\
\hline $\mathrm{Mg}$ & 0.018 & 0.015 & 8.7 & 91.3 & $\mathrm{Ce}$ & 0.039 & 0.034 & 14.4 & 85.6 \\
\hline $\mathrm{Al}$ & 0.017 & 0.015 & 6.1 & 93.9 & $\operatorname{Pr}$ & 0.037 & 0.032 & 0.2 & 99.8 \\
\hline $\mathrm{Si}$ & 0.018 & 0.015 & 5.5 & 94.5 & $\mathrm{Nd}$ & 0.042 & 0.036 & 0.2 & 99.8 \\
\hline $\mathrm{P}$ & 0.018 & 0.015 & 5.9 & 94.1 & $\mathrm{Sm}$ & 0.10 & 0.09 & 0.1 & 99.9 \\
\hline $\mathrm{S}$ & 0.020 & 0.017 & 9.5 & 90.5 & $\mathrm{Eu}$ & 5.8 & 5.0 & 99.3 & 0.7 \\
\hline $\mathrm{Cl}$ & 0.020 & 0.017 & 12.7 & 87.3 & $\mathrm{Gd}$ & 0.095 & 0.081 & 0.1 & 99.9 \\
\hline $\mathrm{Ar}$ & 0.038 & 0.033 & 58.0 & 42.0 & $\mathrm{~Tb}$ & 0.47 & 0.40 & 92.0 & 8.0 \\
\hline $\mathrm{K}$ & 0.019 & 0.016 & 5.7 & 94.3 & Dy & 0.092 & 0.078 & 0.1 & 99.9 \\
\hline $\mathrm{Ca}$ & 0.020 & 0.017 & 5.5 & 94.5 & Ho & 0.062 & 0.053 & 0.1 & 99.9 \\
\hline $\mathrm{Sc}$ & 0.022 & 0.019 & 2.6 & 97.4 & $\mathrm{Er}$ & 0.085 & 0.072 & 0.2 & 99.8 \\
\hline $\mathrm{Ti}$ & 0.019 & 0.017 & 2.0 & 98.0 & $\mathrm{Tm}$ & 0.059 & 0.050 & 0.1 & 99.9 \\
\hline V & 0.019 & 0.017 & 2.1 & 97.9 & $\mathrm{Lu}$ & 1.2 & 1.1 & 96.8 & 3.2 \\
\hline $\mathrm{Cr}$ & 0.020 & 0.017 & 1.6 & 98.4 & Hf & 0.074 & 0.064 & 0.1 & 99.9 \\
\hline $\mathrm{Mn}$ & 0.022 & 0.019 & 1.3 & 98.7 & $\mathrm{Ta}$ & 0.051 & 0.043 & 0.4 & 99.6 \\
\hline $\mathrm{Fe}$ & 0.020 & 0.017 & 1.4 & 98.6 & W & 0.045 & 0.039 & 0.2 & 99.8 \\
\hline $\mathrm{Co}$ & 0.031 & 0.027 & 1.1 & 98.9 & $\mathrm{Re}$ & 0.076 & 0.065 & 0.1 & 99.9 \\
\hline $\mathrm{Ni}$ & 0.022 & 0.019 & 2.4 & 97.6 & Ir & 0.10 & 0.087 & 0.1 & 99.9 \\
\hline $\mathrm{Cu}$ & 0.021 & 0.018 & 1.3 & 98.7 & $\mathrm{Pt}$ & 0.044 & 0.038 & 0.1 & 99.9 \\
\hline $\mathrm{Zn}$ & 0.021 & 0.018 & 1.7 & 98.3 & $\mathrm{Au}$ & 0.069 & 0.060 & 0.1 & 99.9 \\
\hline $\mathrm{Ga}$ & 0.12 & 0.10 & 82.6 & 17.4 & $\mathrm{Hg}$ & 0.090 & 0.080 & 0.1 & 99.9 \\
\hline $\mathrm{Ge}$ & 0.021 & 0.018 & 1.0 & 99.0 & $\mathrm{Tl}$ & 0.045 & 0.039 & 0.1 & 99.9 \\
\hline As & 0.022 & 0.020 & 0.9 & 99.1 & $\mathrm{~Pb}$ & 0.045 & 0.039 & 0.1 & 99.9 \\
\hline $\mathrm{Se}$ & 0.28 & 0.25 & 92.7 & 7.3 & $\mathrm{Bi}$ & 0.047 & 0.040 & 0.1 & 99.9 \\
\hline $\mathrm{Br}$ & 0.32 & 0.27 & 93.1 & 6.9 & Th & 0.055 & 0.046 & 7.2 & 92.8 \\
\hline $\mathrm{Kr}$ & 0.72 & 0.64 & 97.0 & 3.0 & $\mathrm{~Pa}$ & 0.16 & 0.14 & 39.8 & 60.2 \\
\hline $\mathrm{Rb}$ & 0.049 & 0.043 & 53.5 & 46.5 & $\mathrm{U}$ & 0.61 & 0.54 & 92.1 & 7.9 \\
\hline $\mathrm{Sr}$ & 0.089 & 0.077 & 73.7 & 26.3 & ${ }^{235} \mathrm{U}$ & 32.00 & 28.00 & 99.5 & 0.5 \\
\hline $\mathrm{Y}$ & 0.024 & 0.021 & 0.7 & 99.3 & ${ }^{238} \mathrm{U}$ & 0.064 & 0.054 & 25.2 & 74.8 \\
\hline $\mathrm{Zr}$ & 0.025 & 0.021 & 0.6 & 99.4 & ${ }^{239} \mathrm{Pu}$ & 31.00 & 27.00 & 99.4 & 0.6 \\
\hline $\mathrm{Nb}$ & 0.026 & 0.022 & 0.5 & 99.5 & & & & & \\
\hline
\end{tabular}

${ }^{*}$ Results rounded to two significant digits; the average $1 \sigma$ uncertainty in the calculated results is $\sim 1.1 \%$ for the maximum heating rates and $\sim 0.35 \%$ for the average heating rates. 
Table 8. Wire Heating Rate Calculation Results for the Full-Slotted Core in Units of W/g・MW. *

\begin{tabular}{|c|c|c|c|c|c|c|c|c|c|}
\hline Material & Maximum & Average & $\% \mathrm{n}$ & $\% \mathrm{p}$ & Material & Maximum & Average & $\% \mathrm{n}$ & $\% p$ \\
\hline $\mathrm{H}$ & 0.36 & 0.30 & 92.2 & 7.8 & Mo & 0.025 & 0.022 & 3.6 & 96.4 \\
\hline${ }^{2} \mathrm{H}$ & 0.12 & 0.10 & 88.1 & 11.9 & $\mathrm{Tc}$ & 0.031 & 0.028 & 0.4 & 99.6 \\
\hline${ }^{3} \mathrm{H}$ & 0.054 & 0.045 & 82.8 & 17.2 & $\mathrm{Ru}$ & 0.11 & 0.093 & 77.0 & 23.0 \\
\hline $\mathrm{He}$ & 0.056 & 0.047 & 75.4 & 24.6 & $\mathrm{Rh}$ & 0.058 & 0.052 & 0.2 & 99.8 \\
\hline${ }^{3} \mathrm{He}$ & 230.00 & 210.00 & 100.0 & 0.0 & $\mathrm{Pd}$ & 0.028 & 0.025 & 0.3 & 99.7 \\
\hline $\mathrm{Li}$ & 7.3 & 6.6 & 99.8 & 0.2 & $\mathrm{Ag}$ & 0.042 & 0.037 & 0.3 & 99.7 \\
\hline${ }^{7} \mathrm{Li}$ & 0.021 & 0.018 & 42.8 & 57.2 & $\mathrm{Cd}$ & 4.2 & 3.7 & 99.4 & 0.6 \\
\hline $\mathrm{Be}$ & 0.021 & 0.018 & 40.1 & 59.9 & In & 2.0 & 1.8 & 98.7 & 1.3 \\
\hline B & 5.2 & 4.6 & 99.7 & 0.3 & $\mathrm{Sn}$ & 0.045 & 0.039 & 40.8 & 59.2 \\
\hline${ }^{10} \mathrm{~B}$ & 7.1 & 6.2 & 99.7 & 0.3 & $\mathrm{Sb}$ & 0.20 & 0.17 & 86.2 & 13.8 \\
\hline $\mathrm{C}$ & 0.018 & 0.016 & 22.8 & 77.2 & $\mathrm{Te}$ & 0.17 & 0.15 & 83.5 & 16.5 \\
\hline $\mathrm{N}$ & 0.033 & 0.029 & 56.4 & 43.6 & I & 0.031 & 0.028 & 0.2 & 99.8 \\
\hline $\mathrm{O}$ & 0.017 & 0.015 & 15.7 & 84.3 & $\mathrm{Xe}$ & 0.26 & 0.22 & 88.1 & 11.9 \\
\hline $\mathrm{F}$ & 0.017 & 0.014 & 15.3 & 84.7 & Cs & 0.033 & 0.029 & 0.2 & 99.8 \\
\hline $\mathrm{Ne}$ & 0.016 & 0.014 & 10.3 & 89.7 & $\mathrm{Ba}$ & 0.057 & 0.050 & 46.7 & 53.3 \\
\hline $\mathrm{Na}$ & 0.015 & 0.014 & 7.9 & 92.1 & $\mathrm{La}$ & 0.092 & 0.083 & 67.4 & 32.6 \\
\hline $\mathrm{Mg}$ & 0.016 & 0.014 & 8.5 & 91.5 & $\mathrm{Ce}$ & 0.036 & 0.032 & 14.2 & 85.8 \\
\hline $\mathrm{Al}$ & 0.016 & 0.014 & 6.0 & 94.0 & $\operatorname{Pr}$ & 0.034 & 0.030 & 0.2 & 99.8 \\
\hline $\mathrm{Si}$ & 0.017 & 0.014 & 5.3 & 94.7 & $\mathrm{Nd}$ & 0.038 & 0.033 & 0.2 & 99.8 \\
\hline $\mathrm{P}$ & 0.017 & 0.014 & 5.7 & 94.3 & $\mathrm{Sm}$ & 0.091 & 0.081 & 0.1 & 99.9 \\
\hline $\mathrm{S}$ & 0.018 & 0.016 & 9.2 & 90.8 & $\mathrm{Eu}$ & 5.1 & 4.6 & 99.3 & 0.7 \\
\hline $\mathrm{Cl}$ & 0.018 & 0.016 & 12.4 & 87.6 & $\mathrm{Gd}$ & 0.084 & 0.074 & 0.1 & 99.9 \\
\hline $\mathrm{Ar}$ & 0.034 & 0.031 & 57.1 & 42.9 & $\mathrm{~Tb}$ & 0.44 & 0.37 & 91.8 & 8.2 \\
\hline $\mathrm{K}$ & 0.018 & 0.015 & 5.5 & 94.5 & Dy & 0.082 & 0.072 & 0.1 & 99.9 \\
\hline $\mathrm{Ca}$ & 0.018 & 0.016 & 5.3 & 94.7 & Ho & 0.057 & 0.049 & 0.1 & 99.9 \\
\hline $\mathrm{Sc}$ & 0.021 & 0.018 & 2.6 & 97.4 & $\mathrm{Er}$ & 0.075 & 0.067 & 0.2 & 99.8 \\
\hline $\mathrm{Ti}$ & 0.018 & 0.016 & 2.0 & 98.0 & $\mathrm{Tm}$ & 0.052 & 0.046 & 0.1 & 99.9 \\
\hline $\mathrm{V}$ & 0.018 & 0.016 & 2.1 & 97.9 & $\mathrm{Lu}$ & 1.1 & 0.97 & 96.7 & 3.3 \\
\hline $\mathrm{Cr}$ & 0.018 & 0.016 & 1.6 & 98.4 & Hf & 0.067 & 0.059 & 0.1 & 99.9 \\
\hline $\mathrm{Mn}$ & 0.020 & 0.018 & 1.3 & 98.7 & $\mathrm{Ta}$ & 0.047 & 0.040 & 0.4 & 99.6 \\
\hline $\mathrm{Fe}$ & 0.019 & 0.016 & 1.3 & 98.7 & W & 0.041 & 0.036 & 0.2 & 99.8 \\
\hline $\mathrm{Co}$ & 0.027 & 0.025 & 1.1 & 98.9 & $\mathrm{Re}$ & 0.068 & 0.060 & 0.1 & 99.9 \\
\hline $\mathrm{Ni}$ & 0.021 & 0.018 & 2.4 & 97.6 & Ir & 0.090 & 0.080 & 0.1 & 99.9 \\
\hline $\mathrm{Cu}$ & 0.020 & 0.017 & 1.3 & 98.7 & $\mathrm{Pt}$ & 0.039 & 0.035 & 0.1 & 99.9 \\
\hline $\mathrm{Zn}$ & 0.019 & 0.017 & 1.6 & 98.4 & $\mathrm{Au}$ & 0.063 & 0.055 & 0.1 & 99.9 \\
\hline $\mathrm{Ga}$ & 0.10 & 0.091 & 82.0 & 18.0 & $\mathrm{Hg}$ & 0.084 & 0.073 & 0.1 & 99.9 \\
\hline $\mathrm{Ge}$ & 0.019 & 0.017 & 0.9 & 99.1 & $\mathrm{Tl}$ & 0.041 & 0.036 & 0.1 & 99.9 \\
\hline As & 0.021 & 0.018 & 0.9 & 99.1 & $\mathrm{~Pb}$ & 0.040 & 0.036 & 0.1 & 99.9 \\
\hline $\mathrm{Se}$ & 0.25 & 0.23 & 92.5 & 7.5 & $\mathrm{Bi}$ & 0.042 & 0.037 & 0.1 & 99.9 \\
\hline $\mathrm{Br}$ & 0.28 & 0.25 & 92.8 & 7.2 & Th & 0.049 & 0.043 & 7.2 & 92.8 \\
\hline $\mathrm{Kr}$ & 0.64 & 0.58 & 96.9 & 3.1 & $\mathrm{~Pa}$ & 0.14 & 0.12 & 39.6 & 60.4 \\
\hline $\mathrm{Rb}$ & 0.045 & 0.040 & 53.1 & 46.9 & $\mathrm{U}$ & 0.54 & 0.49 & 92.0 & 8.0 \\
\hline $\mathrm{Sr}$ & 0.079 & 0.069 & 72.8 & 27.2 & ${ }^{235} \mathrm{U}$ & 28.00 & 25.00 & 99.5 & 0.5 \\
\hline $\mathrm{Y}$ & 0.022 & 0.020 & 0.7 & 99.3 & ${ }^{238} \mathrm{U}$ & 0.058 & 0.050 & 24.4 & 75.6 \\
\hline $\mathrm{Zr}$ & 0.022 & 0.020 & 0.6 & 99.4 & ${ }^{239} \mathrm{Pu}$ & 27.00 & 25.00 & 99.4 & 0.6 \\
\hline $\mathrm{Nb}$ & 0.024 & 0.021 & 0.5 & 99.5 & & & & & \\
\hline
\end{tabular}

${ }^{*}$ Results rounded to two significant digits; the average $1 \sigma$ uncertainty in the calculated results is $\sim 1.1 \%$ for the maximum heating rates and $\sim 0.35 \%$ for the average heating rates. 
Characterization of heat generation rates is an integral component of the thermal hydraulic, structural, and safety analysis supporting TREAT experiment design (Bess et al., 2016). The heating rates provided herein are those expected for thin wires of material. It is expected that given heating rates for materials and instrumentation experiments would change based on core/assembly arrangement, control rod movement, transient prescription requirements, actual size and mass of test components, and physical placement within the test vehicle. Self-shielding effects, and mixed incorporation of strong absorbers, moderators, or fissile elements may incur deviation of actual experiment heating rates from the reference wire heating rates provided. Planned experimentation in BUSTER may fall within a general safety analysis applicable to instrumentation and materials falling within specified guidelines with minimal facility impact. Planned experiments falling outside a prescribed safety analysis envelope will likely warrant more detailed heat generation rate calculation analysis prior to irradiation testing in TREAT.

\section{Use of Historic TREAT Operational Data to Provide Example Calculations}

A small sample of the many historic transient tests performed in TREAT is given in Table 9. The example transients demonstrate TREAT experiment capabilities with variations in peak power, integrated energy, and pulse length. Core slots within TREAT not only run halfway or fully through the core center, running north to south, but might employ hodoscope assembly elements providing a slot $60.96 \mathrm{~cm}$ (24 in.) or $121.92 \mathrm{~cm}$ (48 in.) in height along the core midplane. Generally, the half-slotted cores would face towards the hodoscope located at the north end of the core; however, this was not always the case. Some core loadings did not incorporate any slotted assemblies. Calculations performed in this study included only core loadings with the 48-in.-high slotted assemblies. 
Table 9. Sample Historic Transient Tests in TREAT.

\begin{tabular}{|c|c|c|c|c|c|c|}
\hline Facility Condition & \multicolumn{6}{|c|}{ Pre-Upgrade } \\
\hline Date & $9 / 19 / 1975$ & $9 / 26 / 1975$ & $8 / 24 / 1979$ & $8 / 29 / 1979$ & $8 / 4 / 1980$ & $8 / 5 / 1980$ \\
Transient Number & 1741 & 1740 & 2150 & 2151 & 2221 & 2222 \\
Transient Type & Natural & Natural & Flat Top & Flat Top & Shaped & Shaped \\
Peak Power (MW) & 19,650 & 20,300 & 82 & 82 & 3,055 & 1,289 \\
Integrated Energy (MJ) & 2,100 & 2,170 & 1,263 & 1,262 & 1,314 & 2,941 \\
Pulse Length (s) & 0.107 & 0.107 & 15.4 & 15.4 & 0.43 & 2.28 \\
Experiment Series & EOS CAL & EOS CAL & J1 & J1 & L01 & L01 \\
Reactivity Inserted $(\Delta \mathrm{k} / \mathrm{k})$ & 4.64 & 4.75 & 1.1 & 1.08 & 1.18 & 1.15 \\
Core Loading & 948 & 952 & 1193 & 1194 & 1239 & 1239 \\
Core Slot & 24-Half & 24 -Half & 48 -Half & 48 -Half & 48 -Half & 48 -Half \\
\hline
\end{tabular}

\begin{tabular}{|c|c|c|c|c|c|c|}
\hline Facility Condition & \multicolumn{2}{|c|}{ Pre-Upgrade } & \multicolumn{4}{|c|}{ Post-Upgrade } \\
\hline Date & $11 / 12 / 1986$ & $11 / 19 / 1986$ & $4 / 13 / 1990$ & $4 / 18 / 1990$ & $10 / 23 / 1990$ & $10 / 25 / 1990$ \\
Transient Number & 2717 & 2718 & 2801 & 2802 & 2810 & 2811 \\
Transient Type & Natural & Natural & Natural & Natural & Flat Top & Flat Top \\
Peak Power (MW) & 15,890 & 16,137 & 18,500 & 18,483 & 51.3 & 51.8 \\
Integrated Energy (MJ) & 1,814 & 1,842 & 2,324 & 2,323 & 648 & 699 \\
Pulse Length (s) & 0.114 & 0.114 & 0.126 & 0.126 & 12.6 & 13.5 \\
Experiment Series & $1 \mathrm{~B}$ & $1 \mathrm{~B}$ & Centaurus & Centaurus & M8-CAL & M8-CAL \\
Reactivity Inserted $(\Delta \mathrm{k} / \mathrm{k})$ & 4.45 & 4.47 & 4.06 & 4.07 & 0.8936 & 0.904 \\
Core Loading & 1410 & 1410 & 1451 & 1451 & 1454 & 1454 \\
Core Slot ${ }^{*}$ & None & None & $24-F u l l$ & $24-F u l l$ & $48-F u l l$ & $48-F u l l$ \\
\hline
\end{tabular}

\begin{tabular}{|c|c|c|c|c|c|}
\hline Facility Condition & \multicolumn{5}{|c|}{ Post-Upgrade } \\
\hline Date & $3 / 13 / 1992$ & $3 / 17 / 1992$ & $3 / 19 / 1992$ & $11 / 4 / 1992$ & $11 / 10 / 1992$ \\
Transient Number & 2849 & 2850 & 2851 & 2870 & 2871 \\
Transient Type & Natural & Natural & Natural & Shaped & Shaped \\
Peak Power $(\mathrm{MW})$ & 5,684 & 14,714 & 11,997 & 151 & 150 \\
Integrated Energy $(\mathrm{MJ})$ & 1,536 & 2,485 & 2,256 & 2,339 & 2,356 \\
Pulse Length $(\mathrm{s})$ & 0.270 & 0.169 & 0.188 & 15.5 & 15.7 \\
Experiment Series & AN-CAL & AN-CAL & AN-CAL & M8-CAL & M8-CAL \\
Reactivity Inserted $(\Delta \mathrm{k} / \mathrm{k})$ & 2.89 & 4.01 & 3.72 & 0.942 & 0.944 \\
Core Loading & 1460 & 1460 & 1460 & 1464 & 1464 \\
Core Slot & 48 -Half & 48 -Half & 48 -Half & 48 -Half & 48 -Half \\
\hline
\end{tabular}

${ }^{*}$ Core loading contains either a half slot, full slot, or no slot. Slotted loadings were formed using either the 24 in. or 48 in. slotted assemblies, as discussed in the text. 
Two major types of transients are exponential or peaked bursts (natural) and shaped power bursts (shaped), where a flat top transient is a shaped transient where a constant elevated core power is maintained for a period of time longer than encountered with a typical natural burst. Exponential bursts are temperature-limited or rod-and-temperature-limited excursions; the latter of which the control rods are dropped to clip the transient short before the temperature limit is reached or to limit the energy deposited on the tail-end of the transient. Shaped power bursts are produced by a step insertion of reactivity followed by reactivity insertion or removal at rates required to produce the desired burst shape; delayed neutron effects and the power history of a given transient impact the maximum energy available during a shaped transient. Up to $120 \mathrm{~kW}$ of thermal power can be provided during steady-state operation of TREAT (ANL/RAS 1972). A significant core upgrade was performed between 1988 and 1990; while most characteristics of the core itself remained unchanged, the arrangement and operation of the control rods is clearly different between core loadings prior to and after this upgrade (Robinson and Bauer 1988, Robinson and Bauer 1994).

As an example application of historical data, with the results provided in this document, it will be assumed that sample irradiations had been performed using the BUSTER irradiation test vehicle placed in the core center and containing a full-length copper wire and a thin gold foil located in the peak flux. Results from this example are tabulated in Table 10. Displacement damage and heating rate calculations for the cases using 24-in slotted assemblies or without a slot were assumed to use the tabulated values for the 48-in.-high half-slotted core just to provide example results for varying core transients. Peak fluxes and fluences, for both neutrons and photons, are also provided for the peak position in BUSTER. The calculations reveal peak neutron flux of approximately $10^{17} \mathrm{n} / \mathrm{cm}^{2} \bullet \mathrm{s}$ comparing well with 
historically reported and measured peak neutron flux (Imel and Hart 1996). Example steady-state cases for $100 \mathrm{~kW}$ of operation for $10 \mathrm{~s}$ is provided for both half- and full-slotted configurations as a reference. 
Table 10. Example Calculation Results Applying Historic Transient Data to MCNP-Generated Values for BUSTER.

\begin{tabular}{|c|c|c|c|c|c|c|c|c|c|c|}
\hline \multirow{2}{*}{$\begin{array}{l}\text { Transient } \\
\text { Number }\end{array}$} & \multirow{2}{*}{$\begin{array}{c}\text { Transient } \\
\text { Type }\end{array}$} & \multirow{2}{*}{$\begin{array}{l}\text { Core } \\
\text { Slot }\end{array}$} & \multicolumn{2}{|c|}{ Peak Flux } & \multicolumn{2}{|c|}{$\begin{array}{l}\text { Peak Total } \\
\text { Fluence }\end{array}$} & \multirow[t]{2}{*}{ Material } & \multicolumn{2}{|c|}{ Displacement Damage } & \multirow{2}{*}{$\begin{array}{c}\text { Heating } \\
\text { Rate }\end{array}$} \\
\hline & & & $\mathrm{n} / \mathrm{cm}^{2} \cdot \mathrm{s}$ & $\mathrm{p} / \mathrm{cm}^{2} \cdot \mathrm{s}$ & $\mathrm{n} / \mathrm{cm}^{2}$ & $\mathrm{p} / \mathrm{cm}^{2}$ & & $\mathrm{DPA} / \mathrm{s}$ & DPA & \\
\hline \multirow{2}{*}{$\begin{array}{l}100 \mathrm{~kW} \\
\text { for } 10 \mathrm{~s}\end{array}$} & Steady-State & 48-Half & $8.64 \mathrm{E}+11$ & $3.20 \mathrm{E}+11$ & $8.64 \mathrm{E}+12$ & $3.20 \mathrm{E}+12$ & $\mathrm{Cu}$ & $1.00 \mathrm{E}-10$ & $1.00 \mathrm{E}-09$ & 0.002 \\
\hline & & & & & & & $\mathrm{Au}$ & $1.30 \mathrm{E}-10$ & $1.30 \mathrm{E}-09$ & 0.007 \\
\hline \multirow{2}{*}{$\begin{array}{l}100 \mathrm{~kW} \\
\text { for } 10 \mathrm{~s}\end{array}$} & Steady-State & 48-Full & $7.79 \mathrm{E}+11$ & $2.89 \mathrm{E}+11$ & $7.79 \mathrm{E}+12$ & $2.89 \mathrm{E}+12$ & $\mathrm{Cu}$ & $9.40 \mathrm{E}-11$ & $9.40 \mathrm{E}-10$ & 0.002 \\
\hline & & & & & & & $\mathrm{Au}$ & $1.10 \mathrm{E}-10$ & $1.10 \mathrm{E}-09$ & 0.006 \\
\hline \multirow[t]{2}{*}{1740} & Natural & 24-Half ${ }^{\dagger}$ & $1.75 \mathrm{E}+17$ & $6.49 \mathrm{E}+16$ & $1.87 \mathrm{E}+16$ & $6.94 \mathrm{E}+15$ & $\mathrm{Cu}$ & $2.03 \mathrm{E}-05$ & $2.17 \mathrm{E}-06$ & 370 \\
\hline & & & & & & & $\mathrm{Au}$ & $2.64 \mathrm{E}-05$ & $2.82 \mathrm{E}-06$ & 1400 \\
\hline \multirow[t]{2}{*}{2150} & Flat Top & 48-Half & $7.08 \mathrm{E}+14$ & $2.62 \mathrm{E}+14$ & $1.09 \mathrm{E}+16$ & $4.04 \mathrm{E}+15$ & $\mathrm{Cu}$ & $8.20 \mathrm{E}-08$ & $1.26 \mathrm{E}-06$ & 1.5 \\
\hline & & & & & & & $\mathrm{Au}$ & $1.07 \mathrm{E}-07$ & $1.64 \mathrm{E}-06$ & 5.7 \\
\hline \multirow[t]{2}{*}{2222} & Shaped & 48-Half & $1.11 \mathrm{E}+16$ & $4.12 \mathrm{E}+15$ & $2.54 \mathrm{E}+16$ & $9.40 \mathrm{E}+15$ & $\mathrm{Cu}$ & $1.29 \mathrm{E}-06$ & $2.94 \mathrm{E}-06$ & 23 \\
\hline & & & & & & & $\mathrm{Au}$ & $1.68 \mathrm{E}-06$ & $3.82 \mathrm{E}-06$ & 89 \\
\hline \multirow[t]{2}{*}{2718} & Natural & None $^{\dagger}$ & $1.39 \mathrm{E}+17$ & $5.16 \mathrm{E}+16$ & $1.59 \mathrm{E}+16$ & $5.89 \mathrm{E}+15$ & $\mathrm{Cu}$ & $1.61 \mathrm{E}-05$ & $1.84 \mathrm{E}-06$ & 290 \\
\hline & & & & & & & $\mathrm{Au}$ & $2.10 \mathrm{E}-05$ & 2.39E-06 & 1100 \\
\hline \multirow[t]{2}{*}{2801} & Natural & $24-F u l l^{\dagger}$ & $1.60 \mathrm{E}+17$ & $5.91 \mathrm{E}+16$ & $2.01 \mathrm{E}+16$ & $7.43 \mathrm{E}+15$ & $\mathrm{Cu}$ & $1.85 \mathrm{E}-05$ & $2.32 \mathrm{E}-06$ & 330 \\
\hline & & & & & & & $\mathrm{Au}$ & $2.41 \mathrm{E}-05$ & $3.02 \mathrm{E}-06$ & 1300 \\
\hline \multirow[t]{2}{*}{2811} & Flat Top & 48-Full & $4.04 \mathrm{E}+14$ & $1.50 \mathrm{E}+14$ & $5.45 \mathrm{E}+15$ & $2.02 \mathrm{E}+15$ & $\mathrm{Cu}$ & $4.87 \mathrm{E}-08$ & $6.57 \mathrm{E}-07$ & 0.88 \\
\hline & & & & & & & $\mathrm{Au}$ & $5.70 \mathrm{E}-08$ & 7.69E-07 & 3.3 \\
\hline \multirow[t]{2}{*}{2850} & Natural & 48-Half & $1.27 \mathrm{E}+17$ & $4.70 \mathrm{E}+16$ & $2.15 \mathrm{E}+16$ & $7.94 \mathrm{E}+15$ & $\mathrm{Cu}$ & $1.47 \mathrm{E}-05$ & $2.49 \mathrm{E}-06$ & 260 \\
\hline & & & & & & & $\mathrm{Au}$ & $1.91 \mathrm{E}-05$ & $3.23 \mathrm{E}-06$ & 1000 \\
\hline \multirow[t]{2}{*}{2871} & Shaped & 48-Half & $1.30 \mathrm{E}+15$ & $4.79 \mathrm{E}+14$ & $2.04 \mathrm{E}+16$ & $7.53 \mathrm{E}+15$ & $\mathrm{Cu}$ & $1.50 \mathrm{E}-07$ & $2.36 \mathrm{E}-06$ & 2.7 \\
\hline & & & & & & & $\mathrm{Au}$ & $1.95 \mathrm{E}-07$ & $3.06 \mathrm{E}-06$ & 10. \\
\hline
\end{tabular}

* Results rounded to two significant digits.

$\dagger$ Tabulated values for the 48-Half-Slotted Core were applied to these examples as calculated values for these loadings were not performed. 
As expected, the total displacement damage is negligible regardless of which example transient test was applied. Heating rates are much greater for natural transients with significant peak powers. Shaped transients and steady-state operations provide significantly smaller heating rates. The selection of a prompt versus delayed energy constant (as discussed in Section 2.B) would have no impact upon the heating rate calculations performed. Use of a prompt energy constant to evaluate the displacement damage results would increase their values by approximately $10 \%$ and be considered a more conservative approach when assessing the absolute magnitude of calculated heating rates instead of the relative ratio to total core power.

As mentioned previously, these example calculations are provided at room temperature when actual transient tests undergo a range of redistributing power and temperature profiles. Historic calculations of TREAT PCF values would be corrected using an experimentally measured TCF, which was multiplied against the PCF (Klotzkin et al., 1984, DeHart et al., 2017). Heating rates of experimental components placed in TREAT would similarly be expected to experience transitory effects. Values of TCF for TREAT core loadings nearly identical to those used in this evaluation were reported to be between 0.94 and 0.99 for a full-slotted core, and between 1.10 and 1.22 for a half-slotted core (Robinson and Bauer 1994). Transient tests just prior to the core upgrade were reported to have TCF values between 0.84 and 0.98 , indicating a clear dependence upon core configuration and operations when performing transient testing in TREAT (Robinson and Bauer 1988). The spread in TCF values indicates that within the purview of the varied core configurations, reactor control strategies, and transient testing needs, computed results likely fall within an engineering judgement of $\pm 20 \%$ of experimentally measured values in TREAT. Currently only experimental testing will be performed to more 
accurately assess TCF until advanced modeling and simulation capabilities can more adeptly tackle transient calculations in TREAT.

\section{Future Work}

As mentioned, there are ongoing efforts at INL to improve the capability to model and simulate 3-D transient tests performed in TREAT (DeHart et al., 2016). Reactor characterization tests are planned to provide experimental data for validation of current and future modeling and simulation capabilities with measurements such as flux and fission rate distributions throughout the core and within the test vehicle position, including transient test measurements; other measurements of interest include core temperature distribution, PCF and TCF, kinetic parameters, reactivity worths, and instrumentation testing (Parry 2018), verifying and validating early characterization efforts (Kirn at al., 1960, Okrent et al., 1960) and M8 series measurements (Robinson and Bauer 1994). Neutron spectra measurements, while not as comprehensive as dosimetry measurements performed at the Annular Core Research Reactor (ACRR) facility at Sandia National Laboratories (SNL) (Parma et al., 2015), are also planned, and likely to be further developed and incorporated in current and future experimentation campaigns. High quality measurements will be evaluated and submitted to the International Handbook of Evaluated Reactor Physics Benchmark Experiments (Briggs and Gulliford 2014). Further characterization analysis of the BUSTER test vehicle includes expansion of the baseline calculations to include safety and design envelope mass limits for test instrumentation and materials, activation analysis, characterization of alloys, and assessment of effects from selfshielding, moderation, and mixed materials containing fissionable and/or strong-absorbing 
material. Construction of the BUSTER test vehicle is ongoing, and experiments will be planned and performed to validate the scoping calculations provided in this analysis.

\section{Conclusions}

The TREAT reactor resumed operations in 2017 to supply nuclear-heated safety research. The MARCH irradiation vehicle system can provide novel means to study materials, fuels, and instrumentation undergoing neutron irradiation. Nuclear characterization of the test environment within the BUSTER capsule of MARCH was investigated using MCNP with ENDF/B-VII.1 nuclear data, which was previously demonstrated to adequately model other aspects of TREAT. Results for neutron flux, photon flux, DPA, and wire heating were computed. Limited historic data were available for comparison against these characterization calculations. However, the historic neutron flux reported for a central void in TREAT compares favorably with current calculations. Sample calculations based upon historic TREAT operational data were performed to provide a comparison of TREAT performance capabilities. These calculations were

performed to provide steady-state baseline reference values typical in both half- and full-slotted TREAT core configurations, enabling design scoping analysis prior to development of more specific design testing needs and transient testing experimentation.

\section{Acknowledgments}

This research made use of the resources of the High-Performance Computing Center at Idaho National Laboratory, which is supported by the Office of Nuclear Energy of the U.S. Department of Energy and the Nuclear Science User Facilities under Contract No. DE-AC07$05 I D 14517$. 


\section{References}

G. A. Freund, H. P. Iskendarian, and D. Okrent, "TREAT, a Pulsed Graphite-Moderated Reactor for Kinetics Experiments," Proc. $2^{\text {nd }}$ United Nations Int. Conf. on the Peaceful Uses of Atomic Energy, Geneva, Switzerland, 10, 461 (1958).

D. R. MacFarlane, G. A. Freund, J. F. Boland, "Hazards Summary Report on the Transient Reactor Test Facility (TREAT),” ANL-5923, Argonne National Laboratory (1958).

N. E. Woolstenhulme, D. M. Wachs, and A. B. Beasley, “Transient Experiment Design for Accident Tolerant Fuels," Trans. Am. Nucl. Soc., 111, 604 (2014).

J. D. Bess and M. D. DeHart, "Baseline Assessment of TREAT for Modeling and Analysis Needs," INL/EXT-15-35372, Idaho National Laboratory (2015).

M. D. DeHart, et al., "Research in Support of TREAT Kinetics Calculations Using Rattlesnake/BISON Coupling within MAMMOTH," Proc. PHYSOR 2016, Sun Valley, ID (1-5 May 2016).

N. E. Woolstenhulme, et al., "New Capabilities for In-Pile Separate Effects Tests in TREAT," Trans. Am. Nucl. Soc., 118, 1567 (2018).

N. Woolstenhulme, et al., "Status Report for NEET In-Pile Sensor Irradiation Capabilities at TREAT," INL/EXT-17-43274, Idaho National Laboratory (2017).

X-5 Monte Carlo Team, “MCNP6 User’s Manual - Code Version 6.1.1beta,” LA-CP-14-00745, Los Alamos National Laboratory (2014).

J. T. Goorley, “MCNP6.1.1-Beta Release Notes,” LA-UR-14-24680, Los Alamos National Laboratory (2014). 
D. Newell, "MCNP Model Validation for TREAT Source Term Generation," TEV-2326, Idaho National Laboratory (2015).

A. S. Chipman, "Verification and Validation of MCNP6.1 for Modeling TREAT Neutronic Performance," ECAR-3846, Idaho National Laboratory (2017).

M. B. Chadwick, et al., "ENDF/B-VII.1 Nuclear Data for Science and Technology: Cross Sections, Covariances, Fission Produce Yields and Decay Data," Nucl. Data Sheets, 112, 2887 (2011).

S. C. Frankle, "Summary Documentation for the ENDL92 Continuous-Energy Neutron Data Library,” LA-UR-96-327, Los Alamos National Laboratory (1996).

E. M. Baum, et al., Nuclides and Isotopes Chart of the Nuclides, Seventeenth Edition, Bechtel Marine Propulsion Corporation, ISBN 978-0-9843653-0-2 (2010).

J. D. Bess, et al., “TREAT Multi-SERTTA Neutronics Design and Analysis Support,” Proc. PHYSOR 2016, Sun Valley, ID (1-5 May 2016).

W. R. Robinson and T. H. Bauer, "The M8 Power Calibration Experiment (M8CAL)," ANLIFR-232, Argonne National Laboratory (1994).

A. De Volpi, et al., "Fast-Neutron Hodoscope at TREAT: Methods for Quantitative Determination of Fuel Dispersal," Nucl. Technol., 56, 141 (1982).

D. L. Chichester, et al., "The TREAT Fast-Neutron Hodoscope and Plans for Restoring it to Operation," Trans. Am. Nucl. Soc., 112, 377 (2015).

J. D. Bess, et al., "Core Power Flattening Studies Supporting Narrowing Transient Pulse Widths in TREAT," Trans. Am. Nucl. Soc., 118, 997 (2018).

J. R. Lamarsh, Introduction to Nuclear Reactor Theory, Addison-Wesley Publishing Company, Reading, MA (1966). 
M. D. DeHart, B. A. Baker, and J. Ortensi, "Interpretation of Energy Deposition Data from Historical Operation of the Transient Test Facility (TREAT)," Nucl. Eng. Des., 322, 504 (2017).

B. T. Rearden and M. A. Jessee, "SCALE Code System," ORNL/TM-2005/39, Version 6.2.2, Oak Ridge National Laboratory (2017).

L. R. Greenwood, “Neutron Interactions and Atomic Recoil Spectra,” PNL-SA-22813, Pacific Northwest National Laboratory (1993).

"Standard Practice for Characterizing Neutron Exposures in Iron and Low Alloy Steels in Terms of Displacements Per Atom (DPA),” ASTM E693-17, ASTM International (2017).

E. A. Read and C. R. E. de Oliveira, “A Functional Method for Estimating DPA Tallies in Monte Carlo Calculations of Light Water Reactors," Proc. M\&C 2011, Rio de Janeiro, Brazil (8-12 May 2011).

M. J. Norgett, M. T. Robinson, and I. M. Torrens, “A Proposed Method of Calculating Displacement Dose Rates," Nucl. Eng. Des., 33, 50 (1975).

D. R. Olander, A. T. Motta, Light Water Reactor Materials, Volume I: Fundamentals, American Nuclear Society, La Grange Park, IL (2017).

L. R. Greenwood and R. K. Smither, "SPECTER: Neutron Damage Calculations for Materials Irradiations," ANL/FPP/TM-197, Argonne National Laboratory (1985).

J. Lindhard, et al., "Integral Equations Governing Radiation Effects (Notes on Atomic Collisions, III)," Mat. Fys. Medd. Dan. Vid. Selsk., 33(10), 1 (1963).

R. E. MacFarlane and D. W. Muir, "The NJOY Nuclear Data Processing System Version 91," LA-12740-M, Los Alamos National Laboratory (1994).

S. J. Zinkle and J. T. Busby, "Structural Materials for Fission \& Fusion Energy," Mater. Today, 12, 12 (2009). 
T. Allen, et al., "Materials Challenges for Nuclear Systems," Mater. Today, 13, 14 (2010).

K. Nordlund, et al., "Primary Radiation Damage in Materials," NEA/NSC/DOC(2015)9, OECD NEA, Paris, France (2015).

R. E. Stroller, L. R. Greenwood, S. P. Simakov, "Primary Radiation Damage Cross Sections," INDC(NDS)0691, IAEA, Vienna, Austria (2015).

A. Yu. Konobeyev, et al., "Evaluation of Effective Threshold Displacement Energies and Other Data Required for Calculation of Advanced Atomic Displacement Cross Section," Nuc. Energy Tech., 3, 169 (2017).

“Technical Specifications for the TREAT Facility,” TS-420, Idaho National Laboratory (2017). “Transient Reactor Test (TREAT) Facility FSAR,” SAR-420, Idaho National Laboratory (2017). R. W. Swanson, "Guide for Irradiation Experiments in TREAT," Z0004-0001-0R-04, Argonne National Laboratory (1991).

“TREAT Baseline Description Document,” ANL/RAS-72-73, Argonne National Laboratory (1972).

R. L. Klueh and D. R. Harries, "High-Chromium Ferritic and Martensitic Steels for Nuclear Applications,” ASTM stock number: MONO3, ASTM, Bridgeport, NJ (2001).

P. J. Maziasz, "Overview of Microstructural Evolution in Neutron-Irradiated Austenitic Stainless Steels," J. Nucl. Mater., 205, 118 (1993).

G. J. Youinou, "Preliminary Options Assessment of Versatile Irradiation Test Reactor: Neutron Fluxes in Test Reactors," INL/EXT-17-40962, Idaho National Laboratory (2017).

N. E. Woolstenhulme, et al., "Capabilities Development for Transient Testing of Advanced Nuclear Fuels at TREAT,” Proc. Top Fuel 2016, Boise, ID (11-16 September 2016). 
W. R. Robinson and T. H. Bauer, "Power Coupling in TREAT M-Series: New Experimental Results from M7CAL and Updated Analyses," ANL-IFR-86, Argonne National Laboratory (1988).

G. R. Imel and P. R. Hart, "The Performance of Hafnium and Gadolinium Self Powered Neutron

Detectors in the TREAT Reactor," Nucl. Instrum. Meth. B," 111, 325 (1996).

G. Klotzkin, et al., “Time Dependence of Test Fuel Power Coupling During Transient Reactor Test Facility Irradiation Experiments," Nucl. Sci. Eng., 86, 206 (1984).

J. R. Parry, “TREAT Reactor Experiment Capability Characterization,” PLN-5439, Idaho National Laboratory (2018).

F. Kirn, et al., "Reactor Physics Measurements in TREAT," ANL-6173, Argonne National Laboratory (1960).

D. Okrent, et al., "The Reactor Kinetics of the Transient Reactor Test Facility (TREAT)," ANL6174, Argonne National Laboratory (1960).

E. J. Parma, et al., "Radiation Characterization Summary: ACRR Central Cavity Free-Field Environment with the 32-inch Pedestal at the Core Centerline (ACRR-FF-CC-32-cl)," SAND2015-6483, Sandia National Laboratories (2015).

J. B. Briggs and J. Gulliford, “An Overview of the International Reactor Physics Experiment Evaluation Project," Nucl. Sci. Eng., 178, 269 (2014). 